\title{
Estimado del costo de inversión
}

\section{José L. Márquez Robles* \\ Eduardo López Sandoval**}

* Ingeniero químico. Ingeniero industrial por la Universidad Nacional de Ingeniería. Profesor en los cursos de especialización "Taller de proyectos y administración de proyectos" de la Pontificia Universidad Católica del Perú

** Bachiller en ingeniería industrial por la Universidad de Lima. Profesor de la Universidad de Lima.

El artículo presenta los criterios más adelantados que se manejan para realizar un costeo primario de los proyectos industriales, los que servirán a los evaluadores para poner parámetros y límites a las inversiones en las etapas de proyectos de preinversión o de perfil industrial. El artículo reúne los criterios de acuerdo con la estructura de Lang, modificado por Peters \& Timmerhaus y los últimos enunciados por Plavsic. 


\section{Introducción}

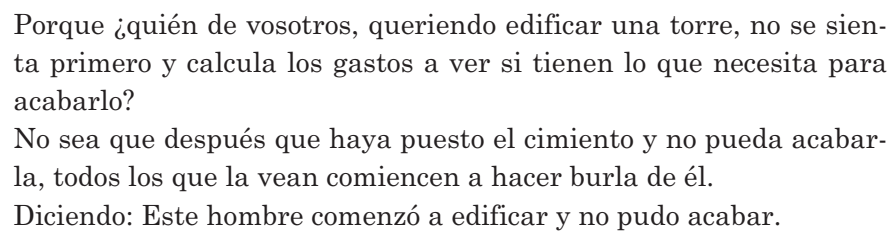

Las frases del evangelista que se glosan en el epígrafe fueron expresadas hace casi dos mil años y, sin embargo, adquieren actualidad cuando constatamos que los proyectos para el desarrollo de nuestro país han sido evaluados a partir de un cálculo indebido de la inversión. Esto se debe al desconocimiento del costo real, en algunos casos, y en otros al optimismo exagerado de algunos proyectistas, que basados en el bajo costo de la mano de obra, desprecian los gastos de instalación del equipo o de las tuberías y minimizan las otras instalaciones y servicios auxiliares, que son indispensables para la operación de planta. Y, lamentablemente, sólo se dan cuenta de ello cuando los préstamos solicitados a largo plazo no son suficientes y la inversión se paraliza por falta de aporte de los socios. Ocurre entonces que si la maquinaria básica está en el país y se ha desaduanado y el capital no alcanza para completar la maquinaria y los servicios, no se puede efectuar el montaje; es necesario, entonces, acudir a la banca local por créditos a corto plazo que incrementan tremendamente la inversión y los costos de producción, debido a los intereses que hay que pagar durante los primeros años de operación, que son los cruciales. Esto genera desánimo en el inversionista, al no recibir una adecuada rentabilidad y encontrarse casi dependiente de los bancos que adjudicaron nuevos préstamos, con el fin de salvar los préstamos primitivos.

El escenario expuesto hace indispensable un acucioso cálculo de la inversión antes de afrontar el proyecto, y las aproximaciones a la inversión deben realizarse desde la primera fase del proyecto, es decir, cuando se concreta la idea y se elabora el perfil del proyecto. Luego, en cada paso del proyecto, como veremos a continuación, el estimado debe de ajustarse hasta llegar a una precisión de $\pm 10 \%$ en la etapa de inversión. 


\section{Definiciones básicas}

Hay algunas definiciones básicas que se debe tener en cuenta al afrontar un proyecto:

\section{La empresa privada}

Es una unidad autónoma que arriesgando cierto capital y esfuerzo reúne los medios de producción necesarios para efectuar una prestación de bienes y servicios o utilitarios destinados al mercado, con el objeto de obtener el máximo beneficio.

\section{El costo de inversión}

Está constituido por todos los recursos y facilidades necesarios para la instalación y puesta en marcha de los medios de producción de bienes y servicios y se forma por la adición de todos los elementos que se incluyen en tres cuentas principales:

\section{El capital inmovilizado, fijo o tangible}

Se emplea en la adquisición de los medios transformadores como maquinaria, aparatos, catalizadores, instrumentos, etc. Este capital se pierde paulatinamente en la operación y es amortizable a través de la depreciación.

\section{El capital previo o intangible}

Es el utilizado en los gastos de gestión del proyecto, permisos, formación de la sociedad, construcciones no permanentes, costos de ingeniería y aun los intereses que son pagados por los préstamos antes del arranque de la planta; y es amortizado durante la vida del proyecto.

\section{Capital circulante o capital de trabajo}

Es aquél que se emplea en la compra de materias primas, insumos y auxiliares, pago de jornales durante los primeros meses de arranque; puede ser dinero efectivo disponible y en todo caso es realizable. 


\section{Utilidad neta}

Es el equivalente al ingreso total del negocio menos todos los costos y gastos que ocasiona la producción.

\section{Factores que afectan el cálculo de la inversión}

El cálculo de la inversión puede ser elevado si existen factores exógenos al proyecto, que presionan sobre los costos de sus diferentes elementos. Pueden ser:

Fuentes de suministro de equipos

El costo del equipo es el factor preponderante de la inversión. Depende del país en que se fabrique y de los cambios económicos que se producen en el mundo; sea por el alto costo de la mano de obra especializada en algunos países altamente industrializados, por el alto costo de los materiales con los que son manufacturados o por el grado de precisión que establecen algunos diseñadores del equipo básico.

El proyectista debe, por lo tanto, ser muy cuidadoso en sus especificaciones ya que si éstas son muy vagas, el constructor de la maquinaria puede elevar el costo de ésta a su criterio.

\section{Fluctuaciones de precio}

Un mismo equipo puede tener como causas económicas diferencias de precio de país a país, lo que hace más complicada la labor de adquisición. Existen ocasiones en que los créditos que llamamos atados nos obligan a comprar maquinaria de mayor costo en el país cedente del crédito, que podría conseguirse a un mejor precio en otros mercados; por otro lado, el tiempo que transcurre entre la decisión y el momento de la compra puede traducirse en un incremento del costo del equipo.

\section{Política de la compañía propietaria}

Hay empresas que por política exigen ciertos usos o parámetros a sus proyectos, cualquiera que sea el lugar donde se realicen. Sistemas contra incendio preestablecidos, exigencias de construcciones cerradas, política social muy desarrollada, alto grado de instrumentación, pueden causar elevaciones en el costo de inversión. 
Tamaño de planta, razón de producción y turnos de operación

Indudablemente que la planta de producción depende de los turnos de operación del proceso, los días de la semana trabajados y las semanas al año de operación. Un proyecto puede tener una inversión sustancialmente menor, si a igual producción trabaja en tres turnos, 330 días al año, que en un turno de 250 días al año.

El tamaño de la planta es el factor más importante del monto de la inversión y, si bien éste tiene una relación estrecha con el mercado a servir, los parámetros entre los que se mueve el monto de la inversión deben estar siempre no sólo sobre el punto de equilibrio económico de la planta (figura $\mathrm{N}^{\circ} 1$ ), sino además encima del punto de mínimo retorno (figura $\mathrm{N}^{\circ} 2$ ) que es el que satisfará el rendimiento económico del proyecto, es decir, el rendimiento de la planta que como empresa cumpla con pagar la utilidad al accionista y los impuestos al Estado.

Figura $\mathbf{N}^{0} 1$

Gráfico del punto de equilibrio económico

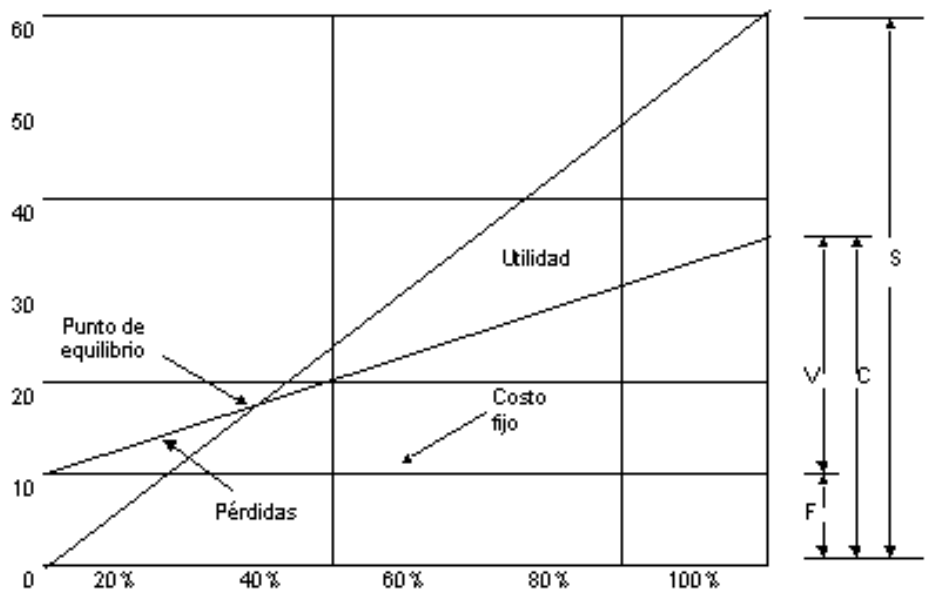

Producción porcentual 


\section{Figura $N^{\circ} 2$ \\ Punto de cierre, equilibrio y mínimo retorno \\ Efecto del costo de operaciones a capacidades menores que el total}
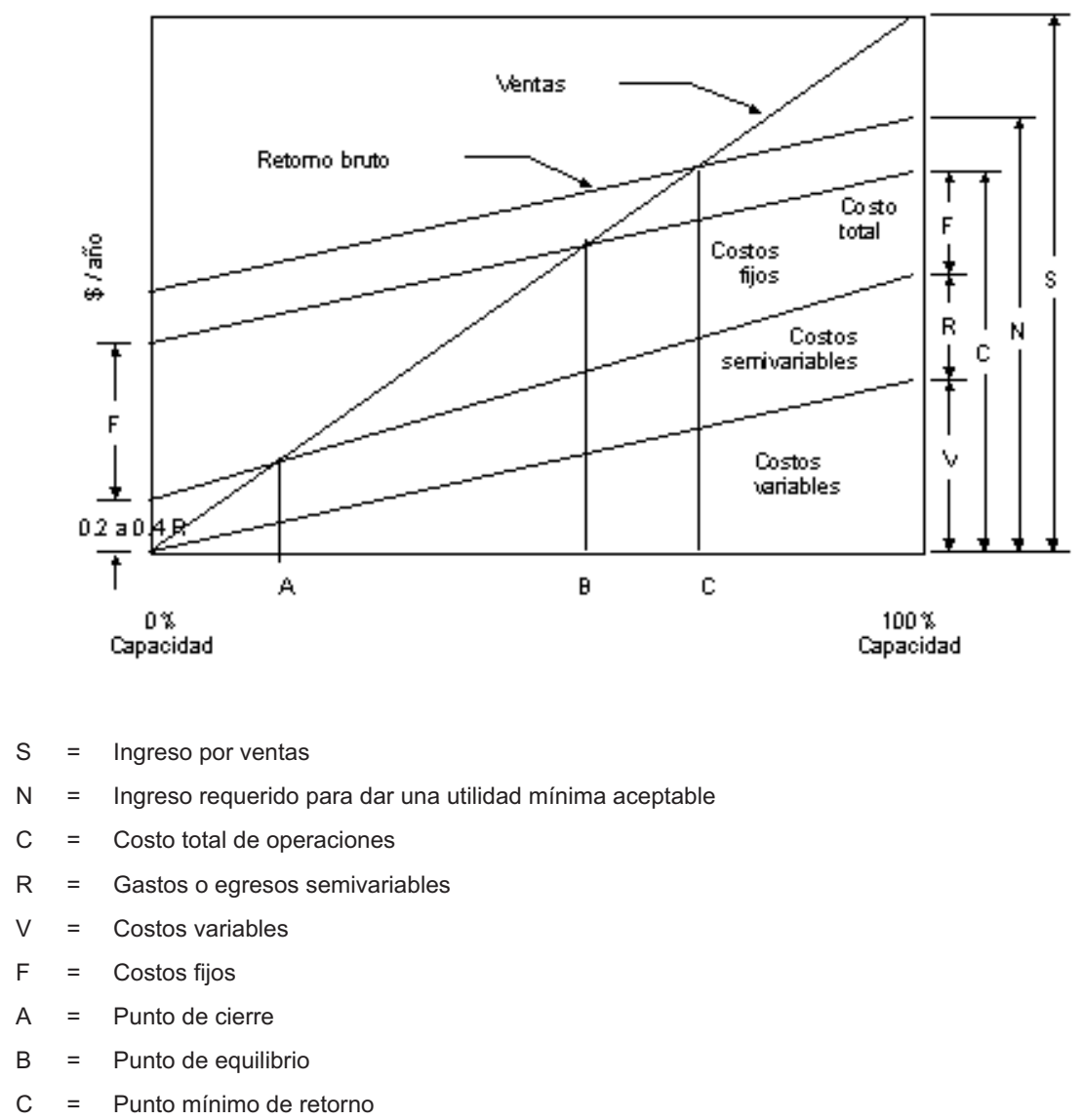

Nivel de la producción

Éste es otro de los factores preponderantes en el costo de inversión, pues cuanto más grande es la planta mayor es el requerimiento de inversión necesario; aun cuando la relación no es lineal porque la inversión creciente en US\$/t tiende a hacerse constante. En nuestros países hay que tener cuidado con los datos que se encuentran en la literatura técnica, ya que la inversión de plantas pequeñas puede dar lugar a costos muy al- 
tos en US\$/t por los cambios tecnológicos que hay que afrontar al realizar la reducción de los tamaños de equipo, si los aparatos usados son muy pequeños con relación a lo estándar, lo que origina un cambio en su valor, que no sigue una proporción directa con el tamaño de equipo (véase regla de Williams, p. 80).

\section{Influencia de la compra de equipo usado o de segundo uso}

Es indudable que la inversión en maquinaria disminuye notablemente si se obtiene maquinaria de segunda mano en buen estado. Existe en los países desarrollados un mercado muy interesante de equipos, muchos de ellos que no han sido utilizados y que son vendidos a precios hasta 50\% menores que el precio de catálogo, por lo que los proyectistas pueden acudir a estos suministradores y, en muchos casos, reducir la inversión total. Hay que tomar en cuenta que el costo de los equipos representa entre $30 \%$ y $40 \%$ de la inversión total, por lo que hay que evaluar razonablemente la magnitud del ahorro.

\section{Proporción de compra de equipo nacional}

En el Perú se ha desarrollado una tecnología muy interesante de construcción de equipo nacional que puede constituir en algunos casos hasta $60 \%$ de la inversión en maquinaria básica. La influencia de la actividad minera y pesquera han sido muy importantes y los precios nacionales pueden ser muy competitivos y de alta calidad, si se tiene una buena inspección y un diseño tecnológico desarrollado. En muchos casos el equipo nacional puede costar entre 50\% y 70\% de cualquier equipo importado, lo que hace recomendable su uso. Por otra parte, equipos como tanquería, torres, etc., deben ser construidos o ensamblados en el Perú por el alto costo de transporte. Además, los equipos que tienen uso de mano de obra masiva en su construcción (pulido de tanques a espejo, etc.) son sin duda más económicos en nuestro medio.

\section{Políticas gubernamentales}

La influencia de las políticas gubernamentales son de especial peso en el costo de la maquinaria y la construcción del equipo. En los momentos de preponderancia de gobiernos estatistas el alto costo de un arancel, a veces de $100 \%$, 150\% o $200 \%$, ele- 
vaba tremendamente la inversión. En la actualidad, felizmente estos aranceles son del 15\% con tendencia a ser disminuidos. Por otro lado, el alto costo de la divisa extranjera cuando existe control de cambios, es otro factor que influye fuertemente en los precios netos de los equipos importados y nacionales (por el componente de material importado que contienen).

Otro factor tal vez indirecto sería la política de reinversión que el gobierno puede tener sobre ciertos sectores, desde que si la reinversión está inafecta a impuestos la tendencia al aporte fresco es mayor, acudiendo menos al préstamo y reduciendo así el costo de intereses. Otro factor sería el apoyo estatal a ciertos sistemas de préstamo como el leasing, usando instrumentos de encaje bancario. El leasing y el autoleasing pueden disminuir el monto de la inversión, aun cuando los costos de producción sean tal vez mayores, dando a los proyectos más consistencia.

\section{Localización}

La ubicación influirá en la inversión, en especial por los costos de transporte al sitio de trabajo, y en los de la construcción y montaje de planta. Si la ubicación está muy lejos de ciudades principales, el costo de vivienda transitoria elevará el costo de la construcción; si el terreno está muy alejado de carreteras o de centros de transformación de corriente eléctrica o de fuentes de agua, pueden elevar sustancialmente la habilitación industrial y el proyecto. En muchos casos, en sitios alejados se hace necesaria una inversión inicial sustancialmente mayor pero en terrenos mejor situados.

La aplicación de la normativa sobre control ambiental y la necesidad del cumplimiento del ISO 14000 hacen necesario un cuidado especial en la microlocalización.

\section{Extensión del diagrama de flujo}

Un diagrama de flujo muy elaborado, con transporte complicado, puede elevar tremendamente el costo de inversión, indudablemente cuanto mayor o más largo sea este diagrama, mayor será la inversión. Un cuidado muy especial debe ser aplicado cuando los diagramas de flujo usen una gran cantidad de servicios y auxiliares (off-sites) caso de vapor, uso de gases inertes, fuerza eléctrica, etc. Estos servicios pueden elevar sustancialmente la inversión (caso de plantas petroquímicas). 
Tamaño de los equipos auxiliares y su ubicación dentro del layout

Ya hemos explicado en el acápite anterior la influencia de los equipos auxiliares en la inversión, su tamaño, capacidad y, en muchos casos, la ubicación lejana de algún servicio puede dar costos muy altos de inversión y transporte de fluidos o sólidos (tuberías, soportes, postes, fajas, etc.)

\section{Grado de instrumentación, automatización y robótica}

Las nuevas tecnologías son cada vez más profusas en automatización y robótica. En algunos casos los nuevos equipos no se han diseñado en base al ser humano (ergonómicos), sino en base a robots. El avance tecnológico eleva tremendamente el costo de instrumentación, aun cuando en muchos casos el costo del equipo básico es disminuido por el uso de una instrumentación o automatización muy elaborada.

\section{Criterios de diseño}

$\mathrm{Al}$ inicio del proyecto, el proyectista tiende a no tomar muy en cuenta este criterio que recién en la ingeniería básica se denota principal. Una planta a prueba de explosión costará entre $30 \%$ y $40 \%$ más que una planta normal; los criterios de corrosión, construcción abierta o cerrada, requerimiento de uso continuado de corriente, etc., son preponderantes en el costo de inversión, siendo conveniente su discusión desde el momento inicial del proyecto.

Las características del diseño influyen fuertemente en el costo de inversión, sin embargo, en muchas ocasiones el proyectista toma nociones de ella en el momento de recibir la ingeniería básica y al calcular una inversión sustancialmente mayor que la que se ha estimado en perfil o aun en el anteproyecto, ya que las especificaciones obligan a adquirir equipos de costo mayor o de inversiones y accesorios totalmente distintos de los que se pensó al iniciar el proyecto.

Una relación enumerativa mas no limitativa es la siguiente:

\section{Construcción de edificios de procesos}

En la construcción de edificios en nuestro país, por lo general se usaba el concreto armado, debido a su bajo costo 
en comparación con los edificios de perfiles de acero. Esta situación está sufriendo modificaciones debido a la reducción de los aranceles del perfil de acero en los últimos años. Por otra parte, la experiencia del profesional peruano en el campo del concreto incrementa esta tendencia. En los proyectos actuales conviene hacer un análisis de la necesidad de uno u otro patrón, ya que si se proyecta que al terminar la vida útil del proyecto el edificio debe ser vendido o demolido, existe entonces una ventaja en el uso de perfiles de acero. Al terminar la vida útil del edificio será más fácil desarmar perfiles que demoler concreto, con la ventaja del primero de que los perfiles serán de fácil venta y el terreno puede quedar libre y estabilizado para su utilización ulterior. Esto puede equilibrar el menor costo del edificio de concreto; la decisión se debe tomar con cierta antelación. La estructura del soporte de maquinaria, áreas limitadas y expansión de edificios a corto plazo se agregan a las anteriores ventajas. Sin embargo, la mayor resistencia a la corrosión, el bajo costo y la durabilidad, sobre todo si las naves a construir son de gran tamaño, son características que favorecen las construcciones de concreto armado.

Si la construcción va a ser de acero (carbon steel) debe efectuarse un análisis posterior si ésta será soldada o empernada, ya que esta segunda posibilidad facilitará las ampliaciones que pueden ser efectuadas en un futuro cercano.

Sean los edificios de concreto o de estructura de acero, tenemos otro criterio de diseño esencial que consiste en el tipo de cerramiento que debe tener:

Construcciones cerradas

La necesidad de aislamiento del entorno, el requerimiento de aire acondicionado, calefacción o la mera protección de la intemperie o de los cambios climáticos son factores que exigen un tipo especial de construcción que puede elevar la inversión. El tener que circunscribir la factoría industrial y los servicios en una caja cerrada de ladrillo y concreto rodeado de jardines, como es en muchos casos la construcción en países de mayor desarrollo económico, también incide en un costo alto del proyecto. 


\section{Construcciones abiertas}

Los países con climas benignos requieren menos cobertura que en lugares donde las condiciones climáticas son hostiles, esto aumenta la tendencia a construcciones abiertas o semicerradas, en especial en nuestra costa. Existen industrias que pueden o deben estar a la intemperie casi en su totalidad, como la petroquímica; esta característica reduce sustancialmente el costo de la inversión en este rubro.

\section{Corrosión}

Los procesos altamente corrosivos requieren ser tomados en cuenta desde el anteproyecto, ya que los costos de recubrimiento, pintura y de defensa contra la corrosión son altos y en muchos casos son preeminentes en la decisión de la distribución de la planta (layout) e incrementa el costo de construcción, acabado y materiales, a un punto tal que la inversión en maquinaria y construcción pueda multiplicarse varias veces sólo por este concepto, los sistemas de protección anódica que hay que usar en algunos casos son menores, y los materiales de construcción de equipo pueden tener un alto grado de sofisticación.

En los casos de construcción, si bien el concreto tiene una menor exposición que los perfiles de acero, se debe tener especial cuidado en recubrirlo en ambientes corrosivos, para evitar sorpresas desagradables. Estos recubrimientos elevan también el costo de construcción. Pero, sin duda, en industrias que tengan la posibilidad de emisión de gases corrosivos es preferible el uso del concreto armado debidamente aislado.

\section{Erosión}

Ésta es otra característica de diseño puntual que puede encarecer un proyecto, por el uso de materiales especiales en los acabados de tuberías y medios de transportes (bombas centrífugas, rotativas, vises sin fin y otros). Por regla general, cualquier transporte de líquidos con sólidos o todo fluido que transporte sólido en suspensión puede causar graves daños a las partes internas del equipo y encarecer 
su diseño; es importante en la evaluación del proyecto tomar en cuenta este criterio.

\section{Temperatura y presión}

La temperatura y presión a la que trabajan los equipos son dos factores de diseño que traen como consecuencia la elevación de los costos de los materiales de construcción de los equipos. El límite de costo de inversión para éstos se encuentra alrededor de temperaturas menores de $220^{\circ} \mathrm{C}$ $\left(400^{\circ} \mathrm{F}\right)$ y una presión de $150 \mathrm{psig}$ ( $\left.\pm 10 \mathrm{~atm}.\right)$. Temperaturas mayores requerían aleaciones de acero distintas de las normales, dado que la resistencia de los materiales, las condiciones de expansión y contracción por el calentamiento y enfriamiento producen fatiga de los materiales, que debe ser tomada en cuenta en el momento del diseño. En general los polímeros orgánicos, como plásticos, ebónitas, cauchos y recubrimientos epóxidos soportan temperaturas menores de las indicadas. Acero inoxidable, recubrimiento con cerámica, aceros especiales requieren el uso de temperaturas y presiones sobre las indicadas, elevando el costo del equipo de procesos. Los límites varían y el costo aún se incrementa por el cuidado en los métodos de construcción, soldadura, juntas de expansión, etc.

\section{Procesos a prueba de explosión}

Muchos procesos que manejan líquidos de bajo punto de ebullición y flash point (punto de explosión) bajo, (bisulfuro de carbono, acetona, exano, éter, etc.) son altamente peligrosos porque sus instalaciones son especiales: por regla general los ambientes cerrados con recirculación y absorción del solvente para su recuperación y el edificio preparado a prueba de explosión, los motores y las fuentes de luz blindadas, así como una especial instalación eléctrica con condulets, también blindados (esto vale con más razón para gases explosivos como el hidrógeno, metano, etano, etc., y oxidantes como el $\mathrm{O}_{2}$ ).

El estimador de la inversión debe tener también cuidado en todo manejo de polvos oxidables, por conducción fluida cuando ésta tiene un tamaño menor a malla 325 (40 micrones), ya que todos los polvos de materiales combustibles 
(u oxidables) pueden ser altamente explosivos al usar aire con más de $12 \%$ de oxígeno para su transporte, requiriendo instalaciones especiales de generación de gas inerte, con el fin de tener atmósferas pobres en $\mathrm{O}_{2}$ y evitando el riesgo de explosión constituido por el proceso de oxidación (combustión) y electricidad estática que se forman en los fluidos en movimiento y en las tuberías de metal. Todas las tuberías deben tener conexiones a tierra comprobada y los pozos de sal necesarios para evitar acumulaciones de corriente estática.

\section{Seguridad}

El alto grado de seguridad que requieren algunos proyectos puede aumentar el costo de inversión. En lo que se refiere a la seguridad contra incendio, no sólo es necesario para evitar pérdidas humanas o materiales sino también para disminuir sustancialmente las primas de seguro que inciden en el costo de producción.

Circuito contra incendio

Muchas operaciones requieren del costo de circuito contra incendios, debiéndose tener especial cuidado en el diseño que involucra el abastecimiento del agua necesaria no menor de $400 \mathrm{~m}^{3}$ y la línea contra incendio por lo general de alta presión (más de 20 atm). Esto encarece los materiales del sistema.

\section{Uso de sprinklers}

Muchas instalaciones, en especial las que manejan inflamables, requieren el costo de toberas de rocío o sprinklers, que por regla general usan circuitos de alta presión para tener un ataque masivo del conato de incendio. Estos circuitos son especiales y requieren de equipo de bombeo por lo general de alto costo. Para las actividades de turismo es importante tener en cuenta el uso de estos sistemas en los dormitorios de hoteles y hosterías, de acuerdo con reglamentos internacionales. 


\section{Seguridad antiterrorista}

El Perú ha pasado por una larga etapa de terrorismo, lo que ha requerido de sistemas especiales de seguridad, cercos altos, vigilancia continua y equipos especiales de resguardo. Si bien el terrorismo ha disminuido, el bandolerismo, que es su secuela, seguirá por largo tiempo; de ahí que nuestros proyectos necesitarán una inversión importante en este rubro.

\section{Política hídrica}

Sin duda uno de los utilitarios más caros del futuro será el agua tratada. Los proyectos del uso masivo de agua, deberán de tener recuperación total de este elemento, por lo que las inversiones se incrementarán cada vez más en el servicio.

Indudablemente, los proyectos pequeños situados en el área urbana seguirán gozando de la acometida del sistema municipal o público de abastecimiento de agua, lo que hará más sencilla la instalación.

Los proyectos mayores deberán incluir sistemas de acometidas a fuentes de agua, como ríos, lagos, etc., que encarecerán la inversión no sólo por el costo de transporte sino también por el de tratamiento.

En caso de la inexistencia de agua superficial o dificultad de obtenerla por las distancias a las que discurren, será necesaria la perforación de pozos artesianos. En los valles agrícolas, éstos podrían perforarse de 30 a $50 \mathrm{~m}$ de profundidad. En casos de ciudades como Lima estos pozos serán perforados a niveles debajo de 100 a $150 \mathrm{~m}$, donde se encuentran napas freáticas que suministran agua abundante en forma continua.

El requerimiento de dureza del agua del proceso es importante en caso de pozos, ya que éstos, por lo general, tienen durezas desde 300 a 1000 ppm de $\mathrm{CaCO}_{3}$ en comparación con 30 a 50ppm de las fuentes de agua superficiales.

Uso de aguas negras

Las aguas de desecho urbano son usadas en ciertas industrias, previo tratamiento y sanitización. Conforme los recursos hidráulicos se acorten y la industria crezca, 
es conveniente tener en cuenta el uso de aguas cloacales que tratarán ya no sólo para la agricultura sino para la industria, con el costo consiguiente del tratamiento.

Uso de agua de mar

Muchos sistemas de enfriamiento usan agua de mar como recurso para eliminar el calor de las reacciones del proceso. Es necesario tener en cuenta el debido tratamiento del agua de mar, en especial el de la costa peruana, por la presencia de la corriente de Humboldt y por su riqueza en plancton que puede traer graves problemas en los sistemas de enfriamiento, debido al crecimiento de algas y a la colección de partículas orgánicas. En muchos casos es preferible extraer el agua de mar de pozos subterráneos contiguos a las playas, de forma de disminuir la materia orgánica, haciéndolas más útiles para el quehacer industrial.

\section{Uso de gases inertes}

El manejo de gases inertes en el proceso incrementa el costo de las instalaciones, dado que cada vez se usan los sistemas de venteo con nitrógeno o gas carbónico; y en casos como en la metalmecánica se usa el argón en soldaduras especiales.

Un cuidado especial debe aplicarse cuando se requiera del gas inerte en unidades a prueba de explosión, en el caso de manejo de inflamables, o de pulverización fina de polvos oxidables que pueden explotar.

\section{Fuerza eléctrica}

- Uso de los servicios que tienen mayor influencia en el costo de inversiones, sin duda la fuerza eléctrica que se constituye en el sistema nervioso de cualquier proceso. Por regla general el circuito interconectado del Perú conduce 300 mil voltios, lo que hace imposible el poder acometerse directamente a él. Por regla general los circuitos de alta tensión -rurales y domésticos- son de 10 mil voltios. Si los proyectos son grandes debe conducirse la corriente a 10 mil voltios dentro del área de la empre- 
sa transformada a 440/220 voltios en los lugares de trabajo.

- La transmisión en 440 a 220 voltios en tramos mayores de $100 \mathrm{~m}$ debe ser evitada por el costo de los cables de conducción y la mala calidad del servicio por las caídas de tensión, cuando la transmisión es en baja tensión.

- Debemos tener especial cuidado cuando el requerimiento de corriente sea continuado (es decir no permite interrupciones o caídas de tensión), por ejemplo el proceso de alta velocidad o especiales, ya que en estos casos se requerirá el sistema UPS (Uninterrupted Power Sistem) con el encarecimiento subsecuente del proyecto.

\section{Servicios de uso de corriente}

Existen servicios que usan gran cantidad de energía, por lo que requerirán alimentación especial de energía y gran consumo de ésta. El proyectista debe tener especial cuidado cuando maneje:

- aire acondicionado

- uso masivo de aire comprimido

- refrigeración

- calefacción.

\section{Grado de contaminación}

La necesidad de reducir a cero la contaminación obliga a inversiones mayores. El proyectista debe tener en cuenta que la eliminación de desechos sólidos, descontaminación de desagües y la eliminación de humos o polvos contaminantes elevan la inversión. Por otro lado, la necesidad de usar el agua recirculándola la mayor de veces posibles, hace necesario inversiones mayores en sistemas de enfriamiento del agua.

\section{Tipos de estimados comerciales}

\section{Estimado de planta battery limits (limites de batería)}

Comprende la inversión del equipo de manufactura, excluye almacenes, plantas auxiliares, edificios y cualquier otra inversión menor que se especifique; excluye el costo, preparación y desarrollo del terreno. 
Estimado de exteriores de los límites de batería (off-sites)

Definido como lo que se encuentra fuera de los diversos límites de batería, agrupados en tres tipos:

- Instalaciones auxiliares. Son aquéllas que dan servicios a las unidades de producción: caldera de generación de vapor, unidades de tratamiento de agua para servicios o proceso, unidades de tratamiento de efluentes, sistema de compresión de aire, sistema de refrigeración de agua, unidades de preparación de reactivos, etc.

- Instalaciones complementarias. Son aquellas que facilitan el funcionamiento global. Entre éstas se incluyen: interconexión de unidades (racks, etc.), sistemas contra incendios y generador de emergencia, talleres permanentes de mantenimiento, laboratorios, oficinas, cafetería, vías de acceso, etc.

- Almacenamiento y manipulación. Comprende, además de materias primas y auxiliares suficientes para un determinado tiempo de funcionamiento y de elementos para almacenar el producto, zonas de preparación final de éste para su distribución y comercialización.

Servicios especiales fuera de los limites del proyecto

Entre éstos están los servicios de descarga de los productos al puerto, servicio de terceros para determinados procesos de producción, etc., fuera de los límites de la planta y que no se incluyen en los tipos de estimados comerciales.

Estimado de planta grass root $o$ green field

Se define como el costo de una planta completa construida en un nuevo terreno. El costo incluye el terreno y el desarrollo del mismo, el costo battery limits y los off-sites.

\section{Estimado de planta "llave en mano" (turn key)}

Toma en cuenta los estimados grass root más el arranque de la planta. El contratista hace todo el trabajo e incluye un precio de seguridad a su costo.

Para mostrar el alcance de los estimados de costos comerciales para un proyecto, mostramos a continuación el siguiente gráfico: 


\section{Estimados de costos comerciales}

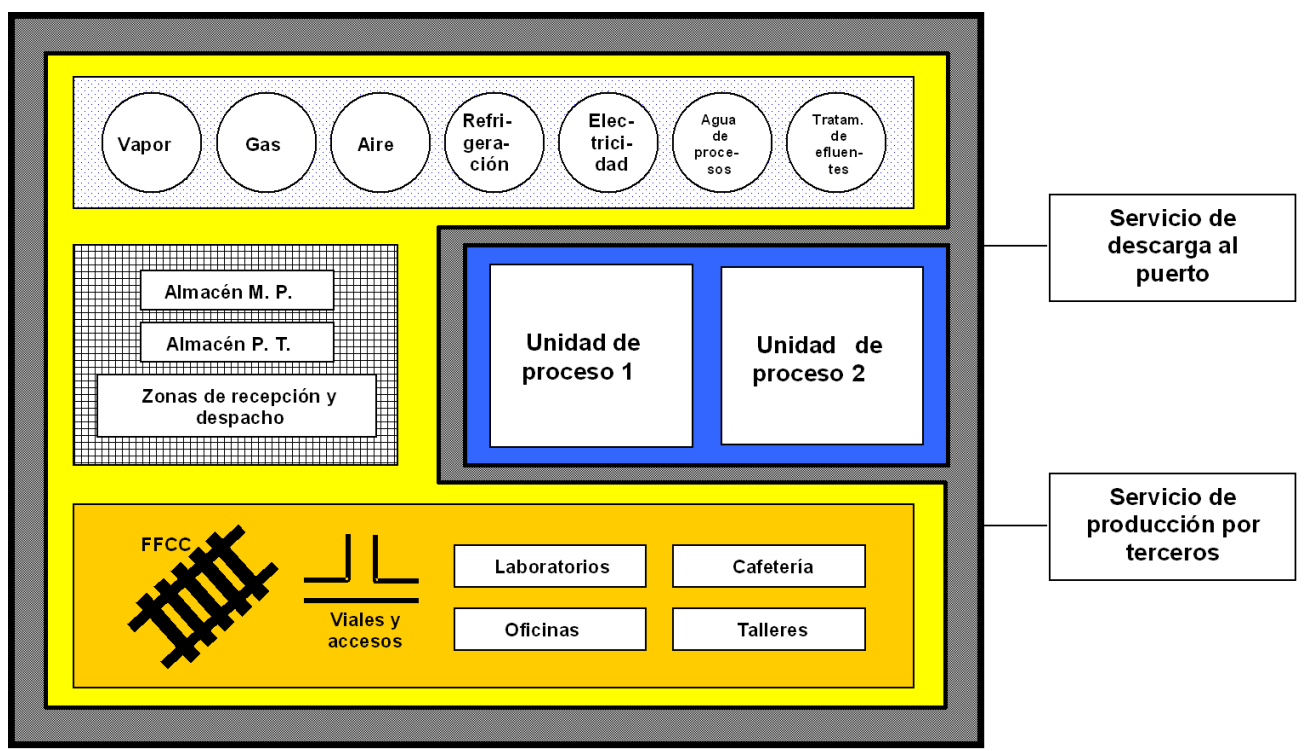

Leyenda

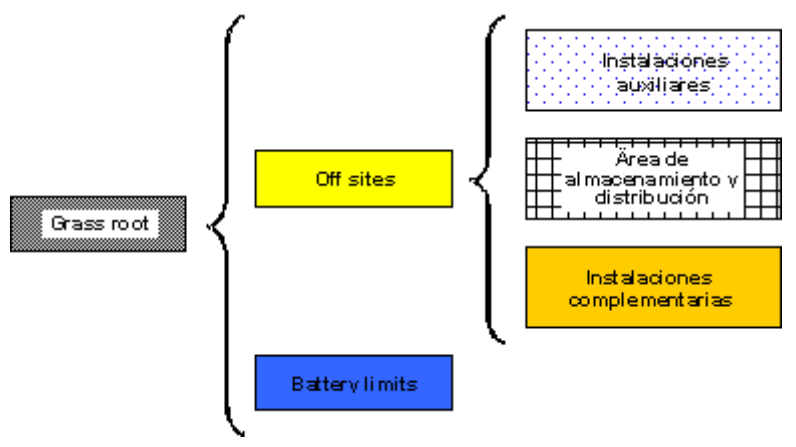




\section{Tipos de estimados de costos}

No amount of engineering will redeem a bad estimate conversely, no "good" estimate will redeem bad engineering.

(La mejor ingeniería no puede recuperar los estragos de un mal estimado. Tampoco el mejor estimado puede sustituir una mala ingeniería).

K. Humphreys.

La experiencia de los últimos 50 años de industria recomienda que durante la vida de un proyecto se realicen por lo menos cuatro estimados de inversión, los que acompañan a cada estudio económico que también deben elaborarse durante el período de estudio del proyecto AACE (American Association of Cost Estimator).

\begin{tabular}{|c|c|c|c|}
\hline Tipo de estimado & Etudio & Precisión & Mátodos de estimación \\
\hline $\begin{array}{l}\text { 1. Orden de magnitud } \\
\text { (blue shy) }\end{array}$ & Perfil & $\begin{array}{l}+50 x \\
-30 x\end{array}$ & $\begin{array}{l}\text { a. Escalamiento } \\
\text { b. Coefciente de circulación o } \\
\text { giro (Tum over ratio) }\end{array}$ \\
\hline $\begin{array}{l}\text { 2. Estudio estimado } \\
\text { (presupuesto preliminar) }\end{array}$ & Anteproyecto & $\begin{array}{l}+30 \% \\
-15 \%\end{array}$ & $\begin{array}{l}\text { a. Lang. Peters \& Tinmertaus } \\
\text { b. Ponderal } \\
\text { c. Porcentaje de costo del equipo } \\
\text { entregado }\end{array}$ \\
\hline 3. Estimado definitivo & Proyecto & $\begin{array}{l}+15 \% \\
-15 \%\end{array}$ & $\begin{array}{l}\text { a. Estimación detallada de los } \\
\text { items en base a cotizaciones } \\
\text { b. Estimación de costo por } \\
\text { unidad } \\
\text { c. Cálculo ponderal } \\
\text { d. Porcentaje de costo de equipo } \\
\text { entregado }\end{array}$ \\
\hline 4. Estimado de finitivo & $\begin{array}{l}\text { Ajuste del proyecto } \\
\text { Resumen ejecutiwo } \\
\text { bancable }\end{array}$ & $\begin{array}{l}+10 \% \\
-10 \%\end{array}$ & $\begin{array}{l}\text { a. Cotiz ación de equipo } \\
\text { b. Cotiz ación de montaje } \\
\text { c. Cálculo ponderal } \\
\text { d. Porcentajes de costo de } \\
\text { equipo entregado }\end{array}$ \\
\hline $\begin{array}{l}\text { 5. Etimado del contratista } \\
\text { (Estimado detallado) }\end{array}$ & $\begin{array}{l}\text { Sólo para } \\
\text { contuatistas }\end{array}$ & $\begin{array}{l}+5 x \\
-5 x\end{array}$ & $\begin{array}{l}\text { a. Cotiz aciones de equipo } \\
\text { b. Cotiz aciones de montaje }\end{array}$ \\
\hline
\end{tabular}

Como podemos apreciar, entre el primer estimado y el último puede haber cerca de 12 a 18 meses. El perfil requiere de un estudio conceptual de la ingeniería, siendo más acucioso el estudio estimado que acompaña el anteproyecto. 
El proyecto requiere, indefectiblemente, de las especificaciones de equipos y tuberías y equipos auxiliares suministrados por la ingeniería básica, por lo que goza de la precisión de cotizaciones más ajustadas del equipo y suministros y tal vez cálculos más exactos del costo de construcción civil.

El ajuste del proyecto debe realizarse en el momento de ejecución de las órdenes de compra y/o al presentar el resumen ejecutivo para solicitar el préstamo bancario; y deben tenerse los datos ajustados de por lo menos el $60 \%$ de los contratos de montaje y construcción.

El estimado del contratista es realizado, por regla general, por los contratistas que presenten cotizaciones tipo grass roots o green field (es decir de la planta completa, sin considerar las acometidas de servicios externos) y, definitivamente, si el contratista va a ofrecer un estimado llave en mano (turn key).

Las técnicas de soporte de los estimados de inversión pueden encontrarse en las siguientes tablas:

Tabla $\mathbf{N}^{\circ} 1$

Orden de magnitud (estimados por relación)

Escalamientos en el tiempo

- Índices de Marshall Swift (Stevens)

- Índices de Chemical Engineering

- Índices de Nelson

- Índices del ENR (Engineering News Record) o de Capeco

Escalamiento en cantidad

Índice de Williams.- Regla de los seis décimos (six tenth factor rule)

Coeficientes de razón de giro de capital (turn over ratio)

Coeficientes de inmovilización unitaria

Métodos de Lang y sus correcciones

Tabla No 2

Estudio estimado

Definición de factores Lang, por Peter \& Timmerhaus, Chilton, modificados a la realidad del proyecto (compartimentación).

- Estimado modular

- Estimado por operaciones unitarias

- Estimado por unidades funcionales 
- Estimado por costo promedio de cada unidad Aplicación de sistemas de Guthrie, Plavsic o sucedáneos Estructuración de los servicios auxiliares (off-sites) Definición de los elementos de equipos y su codificación

Aplicación de métodos ponderal para tanques, depósitos, columnas y otros recipientes

Estimación de potencias y fuentes de energía a instalar

Distribución de factores laborales de instalación

Determinación de mano de obra de operación

Determinación de servicios, tuberías matrices y distribución

Determinación del costo anual de conservación (mantenimiento)

Equipos principales y vida media

Costos de montaje

Presupuesto de límites de batería

Estudio estimado por factores de costo.

Tabla $\mathbf{N}^{\circ} 3$

Estimado definitivo

Ofertas battery limits (límites de batería)

Elaboración de proyectos green field o grass root

Estudios de factibilidad llave en mano (turn key)

Costos de montaje por métodos empíricos, ojimetría, olfato, etc.

Estimación de costos de montaje basándose en estudios distributivos elementales

Ajustes de costos de construcción con contratistas

- Civil

- Conducciones, tuberías de proceso y auxiliares

- Maquinaria de proceso

- Eléctrico

- Instrumental y control

- Eliminación del impacto ambiental

Preparación de listas de órdenes de compra

Reordenamiento del sistema de codificación.

\section{Tabla $\mathbf{N}^{\circ} 4$}

\section{Estimado detallado}

Relación detallada de la maquinaria del proceso y su costo por pieza, tanques, tolvas, columnas, etc.

Listado de conducciones matrices, conexiones (fittings) y válvulas Listado de conducciones de interconexión, conexiones y válvulas Listado de elementos de transporte: bombas, vis sin fin, etc. 
Listado de motores, reductores

Listado de instrumentos, controles PLC, etc.

Edificios de procesos, servicios auxiliares

Acometidas de luz eléctrica, agua, etc.

Control ambiental, desperdicios, desagües, polvos, humos, etc.

Listados eléctricos, transformadores, UPC, arrancadores

Plan de construcción, erección, montaje, relación material-montaje

Programación de recursos por sección

\section{Orden de magnitud}

Escalamientos en el tiempo

Comprende la inflación de los precios del equipo en un tiempo determinado. Debido al problema inflacionario alemán se estableció el Índice Marshall Swift (M\&S) para prevenir el aumento de costos de los equipos.

Posteriormente, a causa de la inflación mundial que generó la guerra de Corea se estableció un índice de Chemical Engineering con base en 1956 y que refleja el crecimiento de la inflación en plantas completas.

Paralelamente, en la industria petrolera y petroquímica se dieron los índices de Nelson-Farrah.

Los indicadores incluyen un ajuste del desarrollo tecnológico en los últimos años.

Índices de Marshall Swift (Stevens)

Éste es el primero y mejor de una serie de índices que se publican para varias industrias.

El índice comienza en 1926, año que se refiere como 100. En su composición incluye costos de los equipos y/o el valor de la mano de obra de la instalación pero no incluye edificios y costos de ingeniería. En realidad es un promedio de los costos individuales de 47 actividades industriales, comerciales y de equipamiento de hogar. Los porcentajes usados se componen de la siguiente forma:

Cemento

Industria química $48 \%$

Productos cerámicos

Vidrio

Pintura 
Papel

Petróleo

Caucho

$$
\begin{array}{r}
10 \% \\
22 \% \\
8 \% \\
100 \%
\end{array}
$$

Índices Marshall Stevens (Swift)

\begin{tabular}{llllllll}
\hline Años & Inflación & Años & Inflación & Años & Inflación & Años & Inflación \\
\hline & & & & & & & \\
1926 & 100,0 & 1965 & 244,9 & 1981 & 721,3 & 1997 & 1056,8 \\
1950 & 167,9 & 1966 & 252,5 & 1982 & 745,6 & 1998 & 1060,0 \\
1951 & 180,3 & 1967 & 262,9 & 1983 & 760,8 & 1999 & 1061,9 \\
1952 & 180,5 & 1968 & 273,1 & 1984 & 780,4 & & \\
1953 & 182,5 & 1969 & 285,0 & 1985 & 789,6 & & \\
1954 & 184,6 & 1970 & 303,3 & 1986 & 797,6 & & \\
1955 & 190,6 & 1971 & 321,3 & 1987 & 813,6 & & \\
1956 & 208,8 & 1972 & 332,0 & 1988 & 852,1 & & \\
1957 & 225,1 & 1973 & 344,1 & 1989 & 895,1 & & \\
1958 & 229,2 & 1974 & 398,4 & 1990 & 915,1 & & \\
1959 & 234,5 & 1975 & 444,3 & 1991 & 930,6 & & \\
1960 & 237,7 & 1976 & 472,1 & 1992 & 943,1 & & \\
1961 & 237,2 & 1977 & 505,4 & 1993 & 964,2 & & \\
1962 & 238,5 & 1978 & 545,3 & 1994 & 993,4 & & \\
1963 & 239,2 & 1979 & 599,4 & 1995 & 1027,5 & & \\
1964 & 241,8 & 1980 & 659,6 & 1996 & 1039,2 & \\
\hline
\end{tabular}

Índices Marshall \& Swift

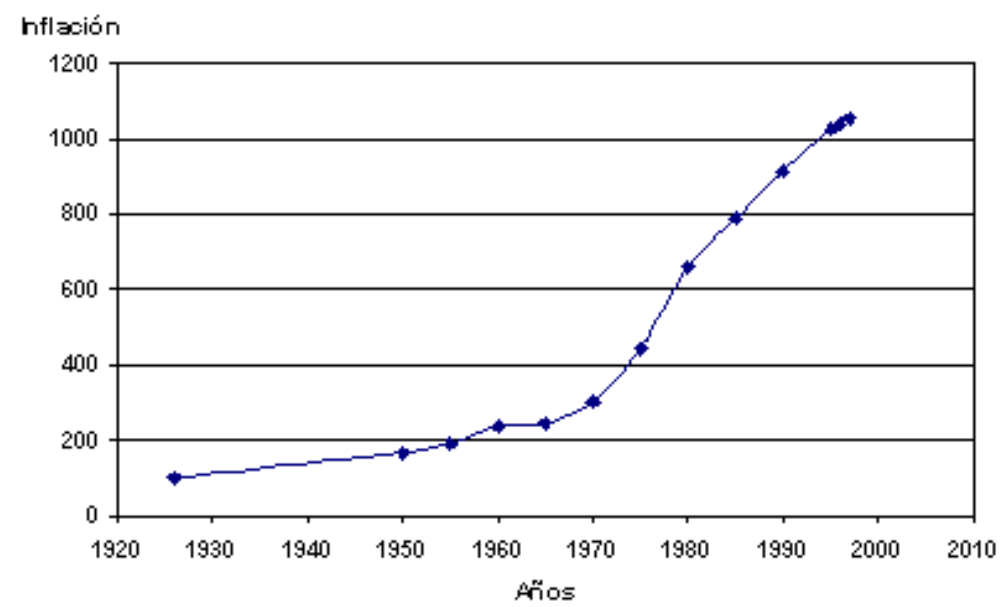


Índices de Chemical Engineering

La revista Chemical Engineering, publicada por McGraw-Hill, contiene desde su iniciación una serie sobre variaciones con la inflación americana de los costos de plantas llamados C.E. Cost Index, este índice se basa en el costo de plantas completas de 1957 a 1959, en el que se toma como base 100. Se publican mensualmente y es un compuesto de:

\title{
Componentes del C.E. Index
}

1957-1959 (100)

\author{
Equipos, maquinaria y soportes \\ Labor de montaje o instalación \\ Labor y materiales de edificio \\ Ingeniería y supervisión
}

$61 \%$

$22 \%$

$7 \%$

$10 \%$

$100 \%$

Índices C.E.CH. Chilton y TH Arnold (Chemical Engineering) (Feb. 1963)

\begin{tabular}{rrrr}
\hline Año & Índice C.E. & Año & Índice C.E. \\
\hline 1950 & 74 & 1980 & 261,2 \\
1955 & 82 & 1981 & 297 \\
1960 & 102 & 1982 & 314 \\
1965 & 104,2 & 1983 & 316,9 \\
1966 & 107,2 & 1984 & 322,7 \\
1967 & 109,7 & 1985 & 325,3 \\
1968 & 113,7 & 1986 & 318,4 \\
1969 & 119 & 1987 & 323,8 \\
1970 & 125,7 & 1988 & 342,5 \\
1971 & 132,2 & 1989 & 355,4 \\
1972 & 137,2 & 1990 & 357,6 \\
1973 & 144,1 & 1991 & 361,3 \\
1974 & 165,4 & 1992 & 358,2 \\
1975 & 182,4 & 1993 & 359,2 \\
1976 & 192,1 & 1994 & 368,1 \\
1977 & 204,1 & 1995 & 381,1 \\
1978 & 218,8 & 1996 & 381,7 \\
1979 & 238,7 & 1997 & 386,5 \\
& & 1998 & 389,5 \\
& & &
\end{tabular}


Con estos datos pueden interpolarse cualquier año. En casos necesarios es útil ir a la fuente del dato en mención, que se publica mensualmente en la Chemical Engineering.

Índices de Chemical Engineering

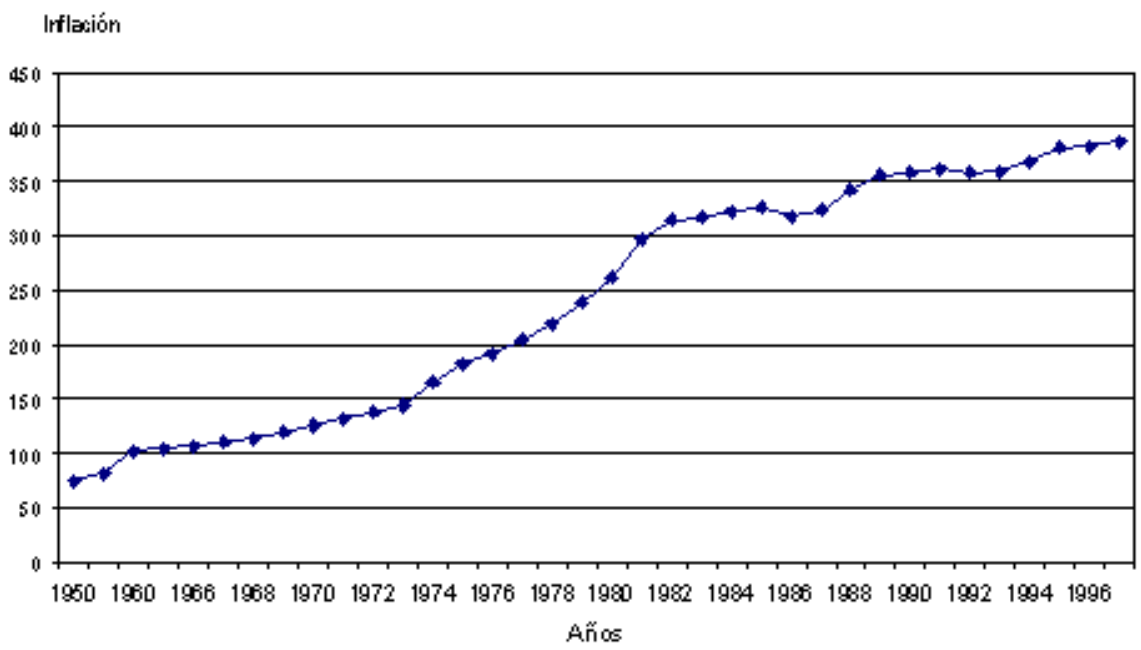

Índices de Nelson-Farrar

Son utilizados para la industria petrolera y petroquímica, usa el año 1946 como base referencial. Se publican en el Oil \& Gas Journal y se aplican proporcionalmente al año de instalación de la planta.

Los índices de Nelson están compuestos por:

Materiales y equipos $40 \%$

hierro y acero $20 \%$

materiales no metálicos para edificaciones $8 \%$ equipos misceláneos fabricados $12 \%$

Salarios $60 \%$ mano de obra especializada $39 \%$ mano de obra común 


\section{Índices Nelson-Farrar}

Refinería de construcción (base 1946)

\begin{tabular}{|c|c|c|c|c|c|c|c|c|}
\hline $\begin{array}{lll}1962 & 1976\end{array}$ & \multicolumn{2}{|c|}{1994} & 1995 & 1996 & 1996 & \multicolumn{2}{|c|}{1997} & $\begin{array}{l}1997 \\
\text { Oct. }\end{array}$ \\
\hline Bombas, compresoras, etc. & 222,5 & 538,6 & 1278,2 & 1316,7 & 1354,5 & 1358,9 & 1390,1 & 1392,9 \\
\hline Maquinaria eléctrica & 189,5 & 287,2 & 560,5 & 563,2 & 561,7 & 558,6 & 553,6 & 553,1 \\
\hline Maquinaria interna & 183,4 & 348,3 & 838,2 & 854,9 & 875,5 & 878,7 & 882,5 & 883,1 \\
\hline Instrumentos & 214,8 & 466,4 & 887,6 & 904,4 & 932,3 & 935,7 & 958,9 & 963,0 \\
\hline Intercambiadores de calor & 183,6 & 478,5 & 690,7 & 758,6 & 793,3 & 789,6 & 757,3 & 773,8 \\
\hline Promedio equipos miscel. & 198,8 & 423,8 & 851,1 & 879,5 & 903,5 & 904,3 & 908,5 & 913,2 \\
\hline Componente de materiales & 205,9 & 445,2 & 877,2 & 918,0 & 917,1 & 917,3 & 924,7 & 927,6 \\
\hline Componente de labores & 258,8 & 729,4 & 1664,7 & 1708,1 & 1753,5 & 1772,6 & 1813,1 & 1817,0 \\
\hline Refinería (inflación) & 237,6 & 615,7 & 1349,7 & 1392,1 & 1418,9 & 14305 & 1457,7 & 1461,3 \\
\hline \multicolumn{9}{|c|}{ Refinería de operaciones (base 1956) } \\
\hline & 1962 & 1976 & 1994 & 1995 & 1996 & 1996 & 1997 & 1997 \\
\hline & & & & & & Oct. & Set. & Oct. \\
\hline Costo de combustible & 100,9 & 384,5 & 447,7 & 461,6 & 546,7 & 576,8 & 516,6 & 562,8 \\
\hline Costo de trabajo & 93,9 & 145,5 & 286,0 & 263,2 & 241,1 & 233,2 & 230,6 & 234,8 \\
\hline Salarios & 123,9 & 314,3 & 903,2 & 900,5 & 884,3 & 872,7 & 926,6 & 930,1 \\
\hline Productividad & 131,8 & 216,1 & 316,7 & 342,9 & 366,9 & 374,2 & 401,9 & 396,0 \\
\hline Investigación & 121,7 & 252,6 & 539,9 & 561,3 & 567,6 & 572,2 & 578,5 & 579,9 \\
\hline Costo de productos químicos & s 96,7 & 195,2 & 213,9 & 245,4 & 252,7 & 252,8 & 254,9 & 255,3 \\
\hline Operaciones de refinería & 108,7 & 209,3 & 405,8 & 410,6 & 413,3 & 415,1 & 411,6 & 418,0 \\
\hline Procesos unitarios & 103,6 & 267,1 & 431,4 & 437,0 & 462,3 & 472,1 & 452,5 & 470,4 \\
\hline
\end{tabular}

Índices del ENR (Engineering News Record) y de Capeco

Son los índices de la construcción civil y reflejan el costo de infraestructura de plantas industriales. Se generan tratando de tener la menor influencia posible de las condiciones locales, por lo que no son costos específicos de plantas de procesos ni de localizaciones fijas.

Los componentes del costo de materiales se basan en los costos de acero, madera de construcción y cemento en cantidades estipuladas por cada índice.

Los índices ENR se dan en dos tablas: la primera de Costos de construcción (usando mano de obra común: peones, albañiles, etc.) y la segunda Costos de edificación (que usan mano de obra calificada: albañiles, 
tuberos, electricistas, etc.). Los índices ENR son más usados en el ámbito internacional y en especial en Estados Unidos, por lo que en la realidad peruana es preferible usar los costos de la Cámara Peruana de la Construcción (Capeco).

Capeco publica mensualmente la revista Construcción e Industria, en la cual se puede encontrar los costos y parámetros de construcción civil y son usadas principalmente para licitaciones y obras públicas. Esta fuente de información sería la más pertinente para los proyectos a realizar en el Perú.

Como se ha especificado anteriormente, la diferencia entre el índice del Costo de Construcción y el Costo de Edificación del ENR está en sus componentes de trabajo.

Cualquier información adicional debe ser conseguida en la revista Engineerig New Records.

Índice ENR para edificaciones (1915-1999)

\begin{tabular}{lccccccccccccc}
\hline & Ene & Feb & Mar & Abr & May & Jun & Jul & Ago & Set & Oct & Nov & Dic & Prom \\
\hline $\mathbf{1 9 7 8}$ & 1609 & 1617 & 1620 & 1621 & 1652 & 1663 & 1696 & 1705 & 1720 & 1721 & 1732 & 1734 & 1674 \\
$\mathbf{1 9 7 9}$ & 1740 & 1740 & 1750 & 1749 & 1753 & 1809 & 1829 & 1849 & 1900 & 1900 & 1901 & 1909 & 1819 \\
$\mathbf{1 9 8 0}$ & 1895 & 1894 & 1915 & 1899 & 1888 & 1916 & 1950 & 1971 & 1976 & 1976 & 2000 & 2017 & 1941 \\
$\mathbf{1 9 8 1}$ & 2015 & 2016 & 2014 & 2064 & 2076 & 2080 & 2106 & 2131 & 2154 & 2151 & 2181 & 2178 & 2097 \\
$\mathbf{1 9 8 2}$ & 2184 & 2198 & 2192 & 2197 & 2199 & 2225 & 2258 & 2259 & 2263 & 2262 & 2268 & 2297 & 2234 \\
$\mathbf{1 9 8 3}$ & 2311 & 2348 & 2352 & 2347 & 2351 & 2388 & 2414 & 2428 & 2430 & 2416 & 2419 & 2406 & 2384 \\
$\mathbf{1 9 8 4}$ & 2402 & 2407 & 2412 & 2422 & 2419 & 2417 & 2418 & 2428 & 2430 & 2424 & 2421 & 2408 & 2417 \\
$\mathbf{1 9 8 5}$ & 2410 & 2414 & 2406 & 2405 & 2411 & 2429 & 2448 & 2442 & 2441 & 2441 & 2446 & 2439 & 2428 \\
$\mathbf{1 9 8 6}$ & 2440 & 2446 & 2447 & 2458 & 2479 & 2493 & 2499 & 2498 & 2504 & 2511 & 2511 & 2511 & 2483 \\
$\mathbf{1 9 8 7}$ & 2515 & 2510 & 2518 & 2523 & 2524 & 2525 & 2538 & 2557 & 2564 & 2569 & 2564 & 2589 & 2541 \\
$\mathbf{1 9 8 8}$ & 2574 & 2576 & 2586 & 2591 & 2592 & 2595 & 2598 & 2611 & 2612 & 2612 & 2616 & 2617 & 2598 \\
$\mathbf{1 9 8 9}$ & 2615 & 2608 & 2612 & 2615 & 2616 & 2623 & 2627 & 2637 & 2660 & 2662 & 2665 & 2669 & 2634 \\
$\mathbf{1 9 9 0}$ & 2664 & 2668 & 2673 & 2676 & 2691 & 2715 & 2716 & 2716 & 2730 & 2728 & 2730 & 2720 & 2702 \\
$\mathbf{1 9 9 1}$ & 2720 & 2716 & 2715 & 2709 & 2723 & 2733 & 2757 & 2792 & 2785 & 2786 & 2791 & 2784 & 2751 \\
$\mathbf{1 9 9 2}$ & 2784 & 2775 & 2799 & 2809 & 2828 & 2838 & 2845 & 2854 & 2857 & 2867 & 2873 & 2875 & 2834 \\
$\mathbf{1 9 9 3}$ & 2886 & 2886 & 2915 & 2976 & 3071 & 3066 & 3038 & 3014 & 3009 & 3016 & 3029 & 3046 & 2996 \\
$\mathbf{1 9 9 4}$ & 3071 & 3106 & 3116 & 3127 & 3125 & 3115 & 3107 & 3109 & 3116 & 3116 & 3109 & 3110 & 3111 \\
$\mathbf{1 9 9 5}$ & 3112 & 3111 & 3103 & 3100 & 3096 & 3095 & 3114 & 3121 & 3109 & 3117 & 3131 & 3128 & 3111 \\
$\mathbf{1 9 9 6}$ & 3127 & 3131 & 3135 & 3148 & 3161 & 3178 & 3190 & 3223 & 3246 & 3284 & 3304 & 3311 & 3203 \\
$\mathbf{1 9 9 7}$ & 3332 & 3333 & 3323 & 3364 & 3377 & 3396 & 3392 & 3385 & 3378 & 3372 & 3350 & 3370 & 3364 \\
$\mathbf{1 9 9 8}$ & 3363 & 3372 & 3368 & 3375 & 3374 & 3379 & 3382 & 3391 & 3414 & 3423 & 3424 & 3419 & 3391 \\
$\mathbf{1 9 9 9}$ & 3425 & & & & & & & & & & & & \\
\hline & & & & & & & & & & & &
\end{tabular}

Base: $1913=100$ 
Índice ENR para construcción (1908-1999)

\begin{tabular}{lccccccccccccc}
\hline & Ene & Feb & Mar & Abr & May & Jun & Jul & Ago & Set & Oct & Nov & Dic & Prom \\
\hline $\mathbf{1 9 7 7}$ & 2494 & 2505 & 2513 & 2514 & 2515 & 2541 & 2579 & 2611 & 2644 & 2675 & 2659 & 2660 & 2576 \\
$\mathbf{1 9 7 8}$ & 2672 & 2681 & 2693 & 2698 & 2733 & 2753 & 2821 & 2829 & 2851 & 2851 & 2861 & 2869 & 2776 \\
$\mathbf{1 9 7 9}$ & 2872 & 2877 & 2886 & 2886 & 2889 & 2984 & 3052 & 3071 & 3120 & 3122 & 3131 & 3140 & 3003 \\
$\mathbf{1 9 8 0}$ & 3132 & 3134 & 3159 & 3143 & 3139 & 3198 & 3260 & 3304 & 3319 & 3327 & 3355 & 3376 & 3237 \\
$\mathbf{1 9 8 1}$ & 3372 & 3373 & 3384 & 3450 & 3471 & 3496 & 3548 & 3616 & 3657 & 3660 & 3697 & 3695 & 3535 \\
$\mathbf{1 9 8 2}$ & 3704 & 3728 & 3721 & 3731 & 3734 & 3815 & 3899 & 3899 & 3902 & 3901 & 3917 & 3950 & 3825 \\
$\mathbf{1 9 8 3}$ & 3960 & 4001 & 4006 & 4001 & 4003 & 4073 & 4108 & 4132 & 4142 & 4127 & 4133 & 4110 & 4066 \\
$\mathbf{1 9 8 4}$ & 4109 & 4113 & 4118 & 4132 & 4142 & 4161 & 4166 & 4169 & 4176 & 4161 & 4158 & 4144 & 4146 \\
$\mathbf{1 9 8 5}$ & 4145 & 4153 & 4151 & 4150 & 4171 & 4201 & 4220 & 4230 & 4229 & 4228 & 4231 & 4228 & 4195 \\
$\mathbf{1 9 8 6}$ & 4218 & 4230 & 4231 & 4242 & 4275 & 4303 & 4332 & 4334 & 4335 & 4344 & 4342 & 4351 & 4295 \\
$\mathbf{1 9 8 7}$ & 4354 & 4352 & 4359 & 4363 & 4369 & 4387 & 4404 & 4443 & 4456 & 4459 & 4453 & 4478 & 4406 \\
$\mathbf{1 9 8 8}$ & 4470 & 4473 & 4484 & 4489 & 4493 & 4525 & 4532 & 4542 & 4535 & 4555 & 4567 & 4568 & 4519 \\
$\mathbf{1 9 8 9}$ & 4580 & 4573 & 4574 & 4577 & 4578 & 4599 & 4608 & 4618 & 4658 & 4658 & 4668 & 4685 & 4615 \\
$\mathbf{1 9 9 0}$ & 4680 & 4685 & 4691 & 4693 & 4707 & 4732 & 4734 & 4752 & 4774 & 4771 & 4787 & 4777 & 4732 \\
$\mathbf{1 9 9 1}$ & 4777 & 4773 & 4772 & 4766 & 4801 & 4818 & 4854 & 4892 & 4891 & 4892 & 4896 & 4889 & 4835 \\
$\mathbf{1 9 9 2}$ & 4888 & 4884 & 4927 & 4946 & 4965 & 4973 & 4992 & 5032 & 5042 & 5052 & 5058 & 5059 & 4985 \\
$\mathbf{1 9 9 3}$ & 5071 & 5070 & 5106 & 5167 & 5262 & 5260 & 5252 & 5230 & 5255 & 5264 & 5278 & 5310 & 5210 \\
$\mathbf{1 9 9 4}$ & 5336 & 5371 & 5381 & 5405 & 5405 & 5408 & 5409 & 5424 & 5437 & 5437 & 5439 & 5439 & 5408 \\
$\mathbf{1 9 9 5}$ & 5443 & 5444 & 5435 & 5432 & 5433 & 5432 & 5484 & 5506 & 5491 & 5511 & 5519 & 5524 & 5471 \\
$\mathbf{1 9 9 6}$ & 5523 & 5532 & 5537 & 5550 & 5572 & 5597 & 5617 & 5652 & 5683 & 5719 & 5740 & 5744 & 5620 \\
$\mathbf{1 9 9 7}$ & 5765 & 5769 & 5759 & 5799 & 5837 & 5860 & 5863 & 5854 & 5851 & 5848 & 5838 & 5858 & 5825 \\
$\mathbf{1 9 9 8}$ & 5852 & 5874 & 5875 & 5883 & 5881 & 5895 & 5921 & 5929 & 5963 & 5986 & 5995 & 5991 & 5920 \\
$\mathbf{1 9 9 9}$ & 6000 & & & & & & & & & & & & \\
\hline
\end{tabular}

Base: $1913=100$

Uso de los índices

Con el fin de evaluar el costo a diferentes momentos en el tiempo usamos la fórmula:

$\mathrm{C}_{2}=\mathrm{C}_{1}\left(\frac{\mathrm{I}_{2}}{\mathrm{I}_{1}}\right)$

Donde:

$\mathrm{I}_{1}=$ es el valor del índice al mes y año 1

$\mathrm{I}_{2}=$ es el valor del índice al mes y año 2

$\mathrm{C}_{1}=$ costo del equipo o planta en el año 1

$\mathrm{C}_{2}=$ costo del equipo o planta en el año 2

Cuando nos encontramos en época de inflación acelerada es preferible usar los índices referidos al mes. 
Ejemplo 1:

La maquinaria y equipo de la planta de etilen glicol costó en 1970 US\$2.300.000. ¿Cuánto costará esta maquinaria en $1997 ?$

\begin{tabular}{cc}
\hline Año 1970 & Año 1997 \\
\hline & \\
$\mathrm{I}_{1}=303,3(\mathrm{M} \& S)$ & $\mathrm{I}_{2}=1056,8(\mathrm{M} \& S)$ \\
$\mathrm{C}_{1}=$ US $\$ 2300000$ & $\mathrm{C}_{2}=?$ \\
\hline
\end{tabular}

$$
\begin{aligned}
& \mathrm{C}_{2}=\mathrm{C}_{1} \times\left(\frac{\mathrm{I}_{2}}{\mathrm{I}_{1}}\right)=2300000 \times\left(\frac{1056.8}{303.3}\right) \\
& \mathrm{C}_{2}=\$ 8013980
\end{aligned}
$$

Ejemplo 2:

La compañía XYZ construyó una planta de etilen glicol terminada en 1970 a un costo de planta de US\$10.000.000. Se desea construir una planta de capacidad similar: ¿Cuál fue su costo a fines de 1997 ?

\begin{tabular}{cc}
\hline Año 1970 & Año 1997 \\
\hline $\mathrm{I}_{1}=125,7$ (C.E.) & $\mathrm{I}_{2}=386,5$ (C.E.) \\
$\mathrm{C}_{1}=$ US\$10. 000. 000 & $\mathrm{C}_{2}=?$ \\
\hline
\end{tabular}

$$
\begin{aligned}
& \mathrm{C}_{2}=\mathrm{C}_{1} \times\left(\frac{\mathrm{I}_{2}}{\mathrm{I}_{1}}\right)=10000000 \times\left(\frac{386.5}{125.7}\right) \\
& \mathrm{C}_{2}=\$ 30747812
\end{aligned}
$$

Debemos recalcar que el uso del CE Index es sólo para plantas completas battery limits o similar, en el caso de tener costo de equipo solamente hay que usar el índice M\&S.

\section{Escalamientos en cantidad}

Índice de Williams. Regla de los seis décimos (six tenth factor rule) 
C.L. Williams encontró que escalonando el precio de los equipos podría conseguirse un exponente constante para varios equipos, tales como intercambiadores de calor, por lo que cuando se trata de escalamiento donde el costo de equipo se conoce, se recomienda usar la fórmula:

$$
\mathrm{C}_{2}=\mathrm{C}_{1} *\left[\begin{array}{l}
\mathrm{Q}_{2} \\
\mathrm{Q}_{1}
\end{array}\right]^{f}
$$

Donde:

$\mathrm{C}_{1}=$ Costo del equipo o recurso de capacidad 1

$\mathrm{C}_{2}=$ Costo del equipo o recurso de capacidad 2

$\mathrm{Q}_{1}=$ Capacidad del equipo o recurso 1

$\mathrm{Q}_{2}=$ Capacidad del equipo o recurso 2

$f=$ Exponente factor de correlación. Cuando no se dispone de mejor información, se puede usar un exponente $f=0,6$

Debemos tener en cuenta que la fórmula es válida cuando la relación $\mathrm{q}_{2} / \mathrm{q}_{1}$ es menor que 10 y que lo que se pretenda estimar sea de una tecnología o tipo lo más parecida posible al dato de referencia.

El índice de Williams, a diferencia del coeficiente de inmovilización unitaria, contempla el "factor de economías de escala" en las estimaciones del equipo, tales como el diseño, materiales de construcción, y para los sistemas de proceso y plantas de procesamiento completas. En el caso de requerir una mayor exactitud al hacer un estimado pormenorizado de equipos, damos unas tablas de los exponentes a usar por equipo:

Exponentes de Williams para equipos

\begin{tabular}{llc}
\hline Clase de aparato & Tipo & Exponente \\
\hline \multirow{3}{*}{ Aspiradores a gas (caudal) } & Centrífugas & 0,87 \\
& De hélice & 0,87 \\
Bombas (caudal) & De vacío & 0,41 \\
& De émbolo & 0,6
\end{tabular}




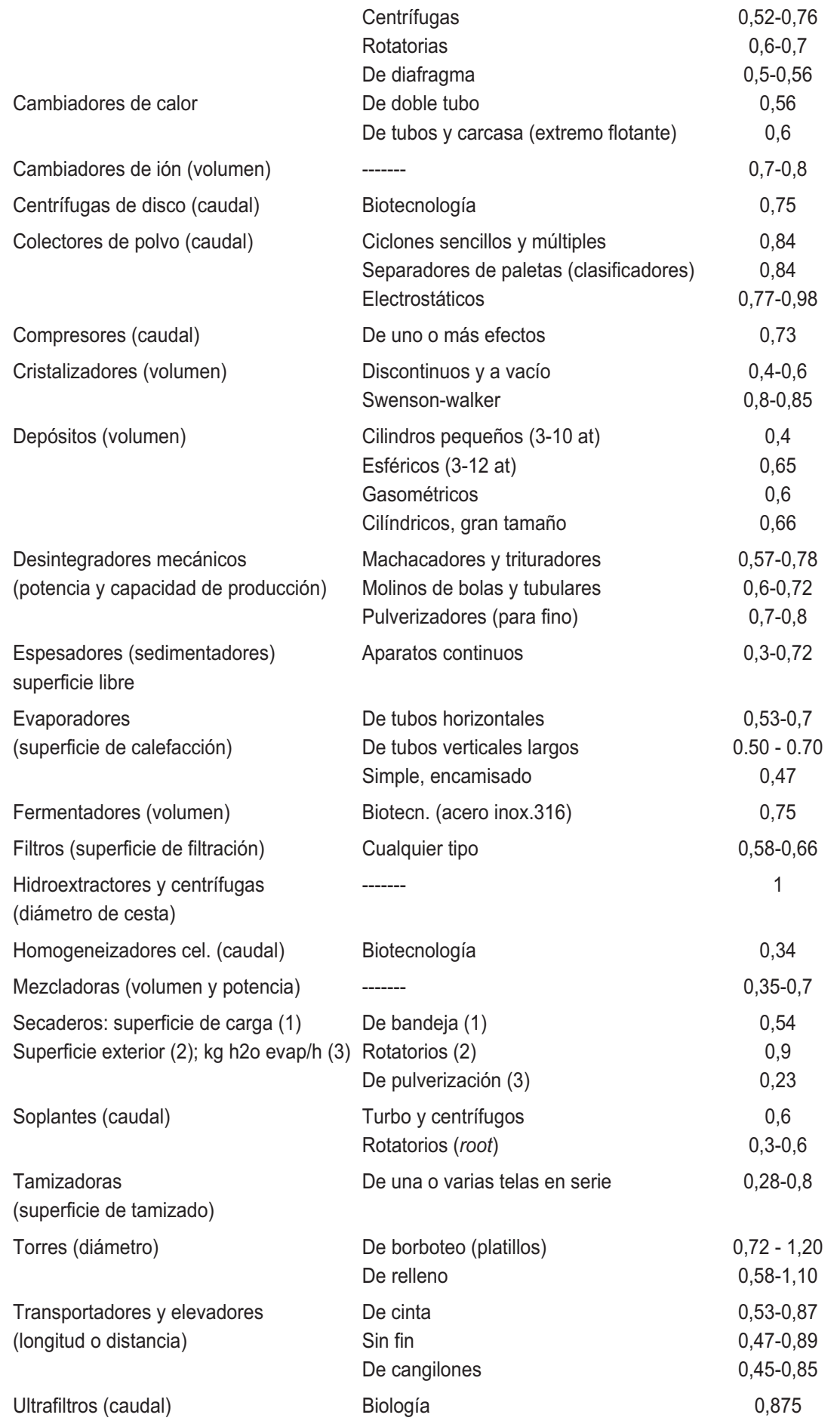




\section{Exponentes de Williams para distintas fabricaciones químicas}

\begin{tabular}{lclc}
\hline Fabricación & $\begin{array}{c}\text { Exponente } \\
\mathbf{f}\end{array}$ & Fabricación & $\begin{array}{c}\text { Exponente } \\
\mathbf{f}\end{array}$ \\
\hline Acetaldehido & 0,70 & Fenol & 0,75 \\
Acetileno & 0,68 & Fosfórico, ácido & 0,60 \\
Acetato de vinilo & 0,65 & Fosfato amónico & 0,68 \\
Agua oxigenada & 0,75 & Formaldehido & 0,55 \\
Alcohilación & 0,60 & Glicol etilénico & 0,70 \\
Alcohol butílico (vía oxo) & 0,50 & Hidrógeno & 0,75 \\
Amoniaco & 0,71 & Isopropanol & 0,60 \\
Azufre & 0,65 & Metanol & 0,71 \\
Benceno & 0,61 & Negro de humo & 0,70 \\
Cloro/sosa & 0,40 & Nitrato amónico & 0,59 \\
Cianhídrico, ácido & 0,71 & Nítrico, ácido & 0,58 \\
Ciclohexano & 0,60 & Nitrilo acrílico & 0,60 \\
Cloruro de vinilo & 0,80 & Oxido de etileno & 0,78 \\
Clorhídrico, ácido & 0,68 & Oxígeno & 0,68 \\
Craqueo a fondo & Polietileno (a.d.) & 0,71 \\
Craqueo catalítico & 0,55 & Polietileno (b.d.) & 0,69 \\
Desparafinado (con disolventes) & 0,55 & Polipropileno & 0,70 \\
Dicloroetano & 0,68 & Reformado catalítico & 0,61 \\
Estireno & 0,71 & Sulfúrico, ácido (azufre) & 0,68 \\
Etanol (síntesis) & 0,67 & Sulfúrico, ácido (pirita) & 0,69 \\
Etileno & 0,70 & Urea & 0,68 \\
\hline
\end{tabular}

Ejemplo:

En 1955, una fábrica de ácido sulfúrico de contacto capaz de obtener 75.000 Tm/año, costó US\$2.000.000: ¿Cuánto costará hoy una fábrica similar de 75.000 Tm/año?

El valor de la inversión de una planta de 75.000 Tm/año en 1991 sería:

$\mathrm{C}_{2}=2000000 * \frac{358}{82}=8731707$

El capital para una capacidad de 15000 t/a. sería :

$$
\begin{aligned}
\mathrm{C} & =8731707 *\left[\frac{150}{75}\right]^{0,64} \\
& =\mathrm{US} \$ 13.536 .765 \\
& =\mathrm{US} \$ 13.500 .000
\end{aligned}
$$


Coeficientes de razón de giro de capital (turn over ratio)

Llámese coeficiente de circulación o coeficiente de giro (turn over ratio), el cociente entre el valor de venta anual y el del capital inmovilizado. Para la industria química este cociente tiene un valor medio de 0,97.

$$
\mathrm{g}=\frac{\mathrm{V}}{\mathrm{I}}
$$

$\mathrm{V}=$ ventas

$\mathrm{I}=$ inversión

luego se puede deducir que:

Inversión fija $=1,03$ ventas

Este coeficiente tiende a aumentar:

- En las fábricas donde predominan las operaciones sobre los procesos.

- Donde la mano de obra y/o la materia prima tienen alta participación en el costo de fabricación.

- Cuando el riesgo de capital es muy elevado.

- En productos de gran novedad en el mercado.

Sin embargo, tiende a disminuir en el valor medio cuando:

- Los productos son de mercado estable.

- La fabricación es de gran capacidad y parte de las materias básicas poco o nada elaboradas.

Este método no puede usarse en estimados para ampliación, modificación o nuevas instalaciones como elementos de producción de otras plantas. 
Valores de "g" para varios tipos de industria

\begin{tabular}{lccc}
\hline Tipo de industria & max. & min. & $\begin{array}{c}\text { valor } \\
\text { medio }\end{array}$ \\
\hline Básica & 1,48 & 0,23 & 0,83 \\
Petróleos & 4,08 & 1,06 & 2,45 \\
Neumáticos & 1,39 & 0,67 & 1,14 \\
Fibras & 0,91 & 0,36 & 0,65 \\
Azucareras & 2,30 & 0,77 & 1,35 \\
Farmacéutica & 5,79 & 0,76 & 3,48 \\
Papeles & 1,60 & 0,36 & 0,90 \\
Materiales de construcción & 0,97 & 0,21 & 0,46 \\
Minero-química & 0,81 & 0,62 & 0,70 \\
\hline
\end{tabular}

Coeficiente de inmovilización unitaria

El coeficiente de inmovilización unitaria será el resultado de la división del capital fijo por la capacidad de la operación.

$$
J=\frac{I}{q}
$$

$\mathrm{I}=$ Inversión fija $\quad \mathrm{q}=$ Capacidad en $\mathrm{TN} /$ año

Es decir, es el valor de la inversión fija necesaria para disponer de una unidad de capacidad de producción anual. Es evidente que cuando se conoce el valor de J para una determinada instalación, bastará con multiplicar por la capacidad de producción de la planta deseada para obtener aproximadamente el valor de su inversión fija.

En su aplicación hay que cuidar de comparar producciones muy similares en capacidad porque supone una estricta proporcionalidad entre la inversión fija y el volumen de producción sin contemplar el factor de "economías de escala". Hay que tener en cuenta que cuando mayor es la producción el valor de $\mathrm{J}$ tiende a disminuir por la economía de escala.

El coeficiente de inmovilización unitaria puede generar problemas para las plantas de menor tamaño, que son las que se usan en nuestra realidad, ya que en plantas pequeñas no se podría hacer una regresión sino los costos unita- 
rios suben sustancialmente; por lo que se necesita cuidado especial en la aplicación de este índice en economías como la peruana.

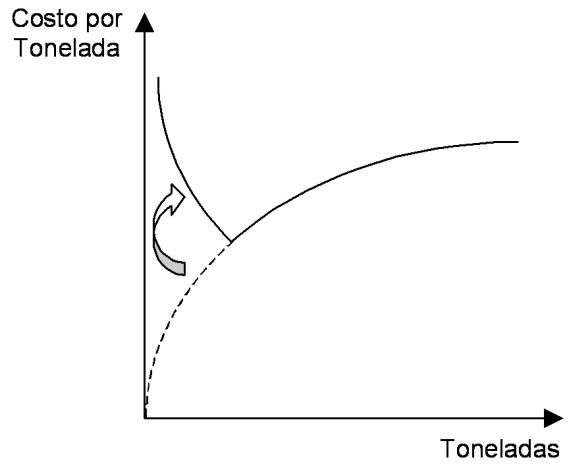

Coeficiente de inmovilización unitaria en algunas plantas químicas (Año 1991)

\begin{tabular}{lrcr}
\hline Compuesto & $\mathbf{Q}(\mathbf{t} / \mathbf{a})$ & $\mathbf{\$}$ Ventas/\$TIC & $\mathbf{\$ T I C / Q}$ \\
\hline & & & \\
Acetaldehido & 50 & 1,84 & 10 \\
Ácido acético & 20 & 1,74 & 40 \\
Acetona & 200 & 3,4 & 140 \\
Acrilonotinio & 300 & 1,4 & 560 \\
Alúmina & 100 & 1,9 & 430 \\
Sulfato alumínico & 25 & 1,5 & 130 \\
Amoníaco & 330 & 0,63 & 130 \\
Nitrato amónico & 300 & 4,6 & 28 \\
Fosfato amónico & 250 & 2,9 & 28 \\
Sulfato amónico & 300 & 3,7 & 22 \\
Benceno & 260 & 8,1 & 51 \\
Butadieno & 250 & 2,9 & 140 \\
Butanol & 100 & 1,4 & 480 \\
Caprolactama & 45 & 1,6 & 1100 \\
Tetracloruro de carbono & 30 & 1,1 & 420 \\
Ciclohexano & 100 & 9 & 61 \\
Difenilamina & 10 & 2 & 2500 \\
Etanol & 30 & 0,14 & 360 \\
Etanoamina & 25 & 6,1 & 700 \\
Etilbenceno & 20 & 0,63 & 160 \\
Etil éter & 35 & 5,7 & 700 \\
Óxido de etileno & 200 & 1 &
\end{tabular}




\begin{tabular}{lrlr} 
Glicerina & 35 & 2,2 & 810 \\
Peróxido de hidrógeno & 200 & 2,5 & 18 \\
Oisopropanol & 150 & 2,5 & 240 \\
Anhidrido maleico & 50 & 5,4 & 200 \\
Metanol & 330 & 0,93 & 110 \\
Metilisobutil cetona & 25 & 1,8 & 400 \\
Ácido nítrico & 200 & 4,1 & 46 \\
Paraxileno & 20 & 0,24 & 1500 \\
Fenol & 200 & 2,1 & 280 \\
Ácido fosfórico & 20 & 2,2 & 270 \\
Polietileno & 20 & 0,38 & 1800 \\
Polipropileno & 20 & 0,32 & 2800 \\
PVC & 200 & 2,7 & 370 \\
Propileno & 20 & 1,9 & 180 \\
Estireno & 500 & 5 & 110 \\
Dióxido de titanio & 50 & 0,58 & 2800 \\
Úrea & 200 & 2,4 & 84 \\
Acetato de vinilo & 200 & 1,9 & 420 \\
Cloruro de vinilo & 500 & 3,3 & 320 \\
\hline
\end{tabular}

Por ejemplo, si una fábrica productora de ácido cianhídrico de capacidad anual $\mathrm{q}=10.000 \mathrm{Tm}$, supone una inversión de 1.200 millones de dólares, su inmovilización unitaria será de $\mathrm{j}=1.200 / 10.000=0,12$

Una fábrica de igual tipo, pero de $12.000 \mathrm{Tm}$ anuales costará $0,12 * 12.000=1.400$ millones de dólares.

\section{Método de Lang y sus correcciones}

Este método ha sido confirmado por la experiencia y sus varios años de difusión. Se basa en la relación que existe entre el capital inmovilizado antes del contratista y el costo de maquinaria y aparatos adquiridos. Existen también otros métodos que han estudiado el tópico, como los de Aston y Meiklejon.

\begin{tabular}{lcc}
\hline Tipos de fabricación & Coeficiente de Lang & $\begin{array}{c}\text { Coeficiente de Aston y } \\
\text { Meiklejon }\end{array}$ \\
\hline Sólidos & 3,10 & 3,00 \\
Semisólidos & 3,63 & 3,60 \\
Fluidos & 4,74 & 4,50 \\
\hline
\end{tabular}


Estos coeficientes se basan en valores medios y se regulan con los criterios siguientes:

- Los coeficientes son menores a los indicados si en la instalación predominan materiales de alto costo como aceros inoxidables, fierro enlozado o vidriado, etc., o tienen el Flowsheet muchos elementos de alto precio.

- Llegando a un mayor grado de precisión N.G. Bach ha propuesto considerar por separado los elementos de proceso, servicio y almacenes con coeficientes distintos así:

$\begin{array}{ll}\text { Maquinaria y aparatos de proceso } & 2,3-4,2 \\ \text { Maquinaria y aparatos de servicios } & 1,7-2,6 \\ \text { Maquinaria y aparatos de almacén } & 2,8-4,8\end{array}$

Con estos coeficientes se llega sólo al costo directo para llegar a la inversión fija total.

Deberá añadirse los gastos de contratista y gastos imprevistos.

Lang toma como punto de partida el costo del equipo directo del proceso, teniendo que evaluar una a una las piezas del equipo. Por lo tanto, este método requiere de mayor información y tiempo para su ejecución, dando estimaciones más precisas que la del orden de magnitud.

\section{Estudio estimado}

Definición de factores Lang, por Peter \& Timmerhaus, Chilton, modificados a la realidad del proyecto (complementación)

Las modificaciones del método de Lang efectuadas por Chilton, parten del valor del equipo instalado. Su instalación varía entre el 40\% y el 70\% del valor del equipo. Además, incluye en la estimación los gastos del contratista y los imprevistos.

La tabla se muestra a continuación: 


\section{Factores de Lang, modificados por Chilton}

\begin{tabular}{llcr}
\hline $\begin{array}{l}\text { Ítem } \\
\mathbf{N}^{\circ}\end{array}$ & \multicolumn{1}{c}{ Concepto } & $\begin{array}{c}\text { Factor } \\
\text { multiplicador }\end{array}$ & $\begin{array}{r}\text { Conce } \\
\text { multiplicad }\end{array}$ \\
\hline 1 & Costo del equipo & 1,00 & 1 \\
2 & Costo del equipo instalado & $1,40-2,20$ & 1 \\
3 & Tuberías del proceso & & \\
& Tipo de planta: & & 2 \\
& Sólidos & $0,07-0,10$ & 2 \\
& Sólidos/fluidos & $0,10-0,30$ & 2
\end{tabular}

$4 \quad$ Instrumentación

Automatización:

$\begin{array}{lll}\text { Poca o ninguna } & 0,02-0,05 & 2 \\ \text { Algo } & 0,05-0,10 & 2 \\ \text { Completa } & 0,10-0,15 & 2\end{array}$

$5 \quad$ Edificios y preparación del terreno Tipo de planta:

$\begin{array}{lc}\text { Existente } & 0.00 \\ \text { Externa } & 0,05-0,20 \\ \text { Mixta } & 0,20-0,60 \\ \text { Interna } & 0,60-1,00\end{array}$

6 Auxiliares (potencia, vapor, agua)

Extensión:

$\begin{array}{lcc}\text { Ninguna } & 0,00 & 2 \\ \text { Ampliación pequeña } & 0,00-0,05 & 2 \\ \text { Ampliación grande } & 0,05-0,25 & 2 \\ \text { Nuevas } & 0,25-1,0 & 2\end{array}$

$7 \quad$ Líneas exteriores

Unidad:

$\begin{array}{lll}\text { Integrada } & 0,00-0,05 & 2 \\ \text { Separada } & 0,05-0,15 & 2 \\ \text { Dispersa } & 0,15-0,25 & 2\end{array}$

8 Costo físico total (conceptos $2-7$ )

9 Ingeniería y construcción

Complejidad:

$\begin{array}{lll}\text { Simple } & 0,20-0,35 & 8 \\ \text { Complicada } & 0,35-0,50 & 8\end{array}$

10 Contingencia y beneficio del contratista Proceso:

Completado

Sujeto a cambios

Especulativo 
Unidad:

$$
\begin{aligned}
& \text { Grande } \\
& \text { Pequeña } \\
& \text { Planta piloto }
\end{aligned}
$$

$$
\begin{aligned}
& 0,05-0,15 \\
& 0,15-0,35
\end{aligned}
$$

$0,15-0,35$

12 Costo total de la planta ( $\Sigma$ conceptos $8-11$ )

Las modificaciones efectuadas por Peters y Timmerhaus, combinan el método de Lang y el de Chilton. Está basado en el costo del equipo instalado, pero mante-

\begin{tabular}{|c|c|c|c|}
\hline \multirow[t]{2}{*}{ Ítem } & \multicolumn{3}{|c|}{ Tipos de proceso } \\
\hline & Sólidos & Semifluidos & Fluidos \\
\hline
\end{tabular}
niendo la clasificación de Lang en plantas de proceso: sólido, semifluido y fluido.

\section{Factores de Lang, modificados por Peters y Timmerhaus (expresados en \% del valor del equipo)}

A. Costo directo

A.1 Equipo comprado

$\begin{array}{rrr}100 & 100 & 100 \\ 45 & 39 & 47 \\ 9 & 13 & 18 \\ 16 & 31 & 66 \\ 10 & 10 & 11 \\ 25 & 29 & 18 \\ 13 & 10 & 10 \\ 40 & 55 & 70 \\ 6 & 6 & 6 \\ 264 & 293 & 346\end{array}$

Total directos

A.3 Instrumentos y control (instalados)

A.4 Tuberías (instalados)

A.5 Eléctricos (instalados)

A.6 Edificios (incluye servicios)

A.7 Mejoras del terreno

A.8 Servicios auxiliares (instalados)

A.9 Terreno

B. Costo indirecto

B.1 Ingeniería de supervisión

B.2 Gastos de construcción

B.3 Contratista

B.4 Contingentes

Total indirectos

Capital fijo para la inversión $(A+B)$

C. Capital de trabajo

68


La tabla da un valor de 100 al costo de los aparatos y maquinarias puestas en el almacén, por lo que deben conocerse los costos FOB, sumarle los fletes, gastos de aduana, IGV, seguros, etc., que en el Perú eleva el FOB en cerca del $55 \%-60 \%$ (1991) para los aparatos comprados en el exterior y en $10 \%$ para los de fabricación local.

\section{Aplicación de sistemas de Guthrie, Plavsic o sucedáneos}

El método de Guthrie divide un proyecto en partes llamadas módulos, clasificados en seis tipos:

- Proceso químico

- Manejo de sólidos

- Preparación de terreno

- Edificios industriales

- Off sites

- Costos indirectos.

Para cada una de estas partes, define una serie de factores partiendo del costo FOB del equipo (E). Estos factores son:

- Factor material (m). Aquél que relaciona el equipo con el resto de elementos físicos de la planta: tuberías, instrumentos, electricidad, hormigón, acero estructural, aislamiento y pintura.

- Factor material directo (M). Es la suma del factor material y el costo del equipo $(\mathrm{M}=\mathrm{m}+\mathrm{E})$.

- Factor mano de obra (L). Relaciona el equipo con el costo de la instalación del mismo y los materiales.

- Factor relación L/M. Relaciona el valor de la mano de obra con el material directo.

- Factor costo directo. Es la suma del factor material directo y el factor mano de obra.

- Factor indirecto. Contempla el costo de la ingeniería, supervisión de la construcción, transporte, etc.

Además de estos factores se pueden usar otros globales, como el módulo total o módulo simple. Para entender con mayor facilidad esta clasificación, presentamos el siguiente cuadro: 


\section{Método de Guthrie}

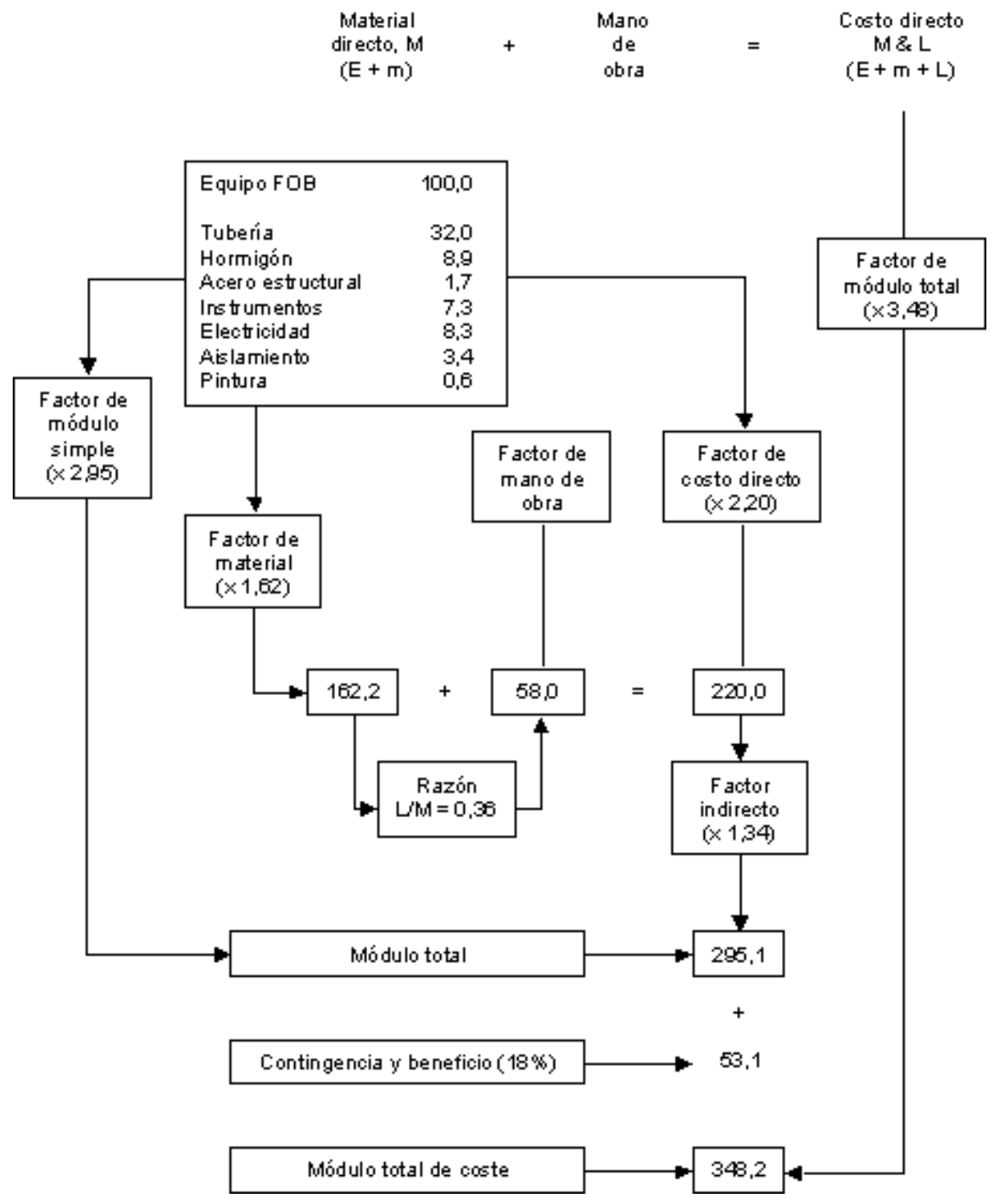

El sistema de Plavsic es un modelo modular aplicable en las regiones industrializadas de Croacia y sus países vecinos, para industrias de procesamientos químicos y de tratamiento de sólidos que parte del costo FOB del equipo principal del proceso (E), calculando el costo del material directo (M) de la siguiente manera:

$$
\mathrm{M}=\mathrm{E}+\mathrm{m}
$$


Donde " $\mathrm{m}$ " representa el costo del material asociado, tales como tuberías, instrumentación, aislantes y soportes. Es común utilizar un "factor de material" para estimar el costo directo del material. Por ejemplo, para una mezcla típica del equipo, Guthrie prescribe $1,62 * \mathrm{E}$ para el proceso químico, y 1,27*E para el tratamiento de los sólidos. Usando estos factores o multiplicadores, un ingeniero de costos puede llegar fácilmente a una buena aproximación a los costos de materiales basados directamente en los de Estados Unidos.
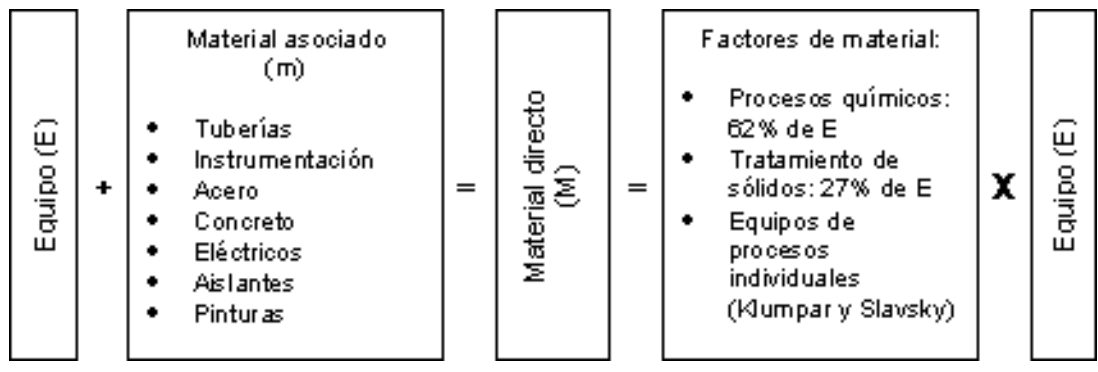

Plavsic introduce el concepto de ajuste de compra $(\mathrm{P})$ en el cálculo del costo directo local, que resulta de ponderar los ratios de impuesto de importación y de disparidad del costo local en comparación con el costo en Estados Unidos con la porción de material directo que será importado y la porción que será de fabricación local, respectivamente. $\mathrm{P}=$ parte local $\mathrm{x}$ ratio de disparidad + parte importada $\mathrm{x}$ ratio de impuesto a la importación

Siendo:

Parte local + parte importada $=1$

El ajuste de compra puede ser negativo cuando los precios de los componentes fabricados localmente son sustancialmente menores que los cotizados en Estados Unidos. Luego, el costo directo se calcula de la siguiente manera: Costo directo (local) $=\mathrm{M}+\mathrm{L}+\mathrm{P}$

Siendo:

$\mathrm{M}=$ costo de material directo.

$\mathrm{L}=$ Trabajo localmente tasado para la instalación. $\mathrm{P}=$ ajuste de compra. 
A partir del costo directo, se calcula el costo total neto $(\mathrm{N})$ $\mathrm{N}=$ costo directo + seguros y fletes + construcción + ingeniería

Para llegar al costo neto del módulo, sumamos los impuestos locales $(\mathrm{T})$ :

Costo neto del módulo $=\mathrm{N}+\mathrm{T}$

Finalmente, el costo total del módulo se obtiene añadiéndoles al costo neto del módulo los honorarios (F) y las contingencias $(\mathrm{C})$ :

Costo total del módulo $=$ costo neto del módulo $+\mathrm{F}+\mathrm{C}$

A continuación, mostramos este sistema para plantas químicas moderadamente complejas en Croacia:

\begin{tabular}{|c|c|c|}
\hline Ítems & Relaciones & $\$$ \\
\hline Equipo FOB (E) & & 100 \\
\hline Material asociado (m) & $62 \%$ de $\mathrm{E}$ & 62 \\
\hline Material directo EE UU (M) & $E+m$ & 162 \\
\hline Ajuste de compras $(P)$ & $26 \%$ de $M$ & 42 \\
\hline Labor de instalación (L) & $40 \%$ de $\mathrm{M}$ & 65 \\
\hline Costo directo (local) & $M+P+L$ & 269 \\
\hline Seguros y flete & $10 \%$ de $\mathrm{M}$ & 16 \\
\hline Construcción & $80 \%$ de $L$ & 52 \\
\hline Ingeniería & $18 \%$ de $M$ & 29 \\
\hline Costo total neto $(\mathrm{N})$ & Costo directo + lo de arriba & 366 \\
\hline Impuestos locales (T) & $5 \%$ de $\mathrm{N}$ & 19 \\
\hline Costo neto del módulo & $\mathrm{N}+\mathrm{T}$ & 385 \\
\hline Honorarios $(F)$ & $3 \%$ del costo neto del módulo & 11 \\
\hline Contingencias $(\mathrm{C})$ & $15 \%$ del costo neto del módulo & 58 \\
\hline Costo total del módulo & $(\mathrm{N}+\mathrm{T})+\mathrm{F}+\mathrm{C}$ & 454 \\
\hline
\end{tabular}

- Estimado modular

- Estimado por operaciones unitarias

- Estimado por unidades funcionales

- Estimado por costo promedio de cada unidad.

Estructuración de los servicios auxiliares (off sites)

Los servicios auxiliares incluyen tres tipos de instalaciones: auxiliares (utilities), complementarias (facilities) o servicios (services) y almacenamiento y manipulación. 
Las instalaciones auxiliares son aquéllas que presentan servicios a las unidades de producción como son: caldera de generación de vapor, unidades de tratamiento de agua para servicios o proceso, unidades de tratamiento de efluentes, sistema de compresión de aire, sistema de refrigeración de agua, unidades de preparación de reactivos, etc.

Las instalaciones complementarias facilitan el funcionamiento global. Entre éstas se incluyen: interconexión de unidades (racks, etc.), sistemas contra incendios y generador de emergencia, talleres permanentes de mantenimiento, laboratorios, etc.

El área de almacenamiento y manipulación comprende, además de materias primas y auxiliares suficientes para un determinado tiempo de funcionamiento y de elementos para almacenar el producto, zonas de preparación final de éste para su distribución y comercialización.

\section{Bibliografía}

Humphreys, Wellman

Basic Cost Engineering. 3a. edición. Nueva York: Marcel Dekker Inc., 1996.

Ludwig, Ernest

Applied Project Engineering and Management. 2a edition. Golf Publishing, 1998.

McGraw-Hill

Chemical Engineering. Revista mensual. Nueva York. Page, John S.

Conceptual Cost Estimating Manual. Golf Publishing Co., 1996.

Peters \& Timmerhaus

Plant Design Economics for Chemical Engineers. 4a Edition. New York: Mc Graw-Hill, 1991.

Sweting, Jack

Project Cost Estimating. Rugby U. K: I Chem E, 1997

Vian O., Ángel

El pronóstico económico en química industrial. Madrid: Eudena S.A./Universidad Complutense de Madrid, 1991. 